\title{
Neoichnology of the desert scorpion Hadrurus arizonensis: burrows to biogenic cross lamination
}

\author{
Daniel I. Hembree, Lee M. Johnson, and Robert W. Tenwalde
}

\begin{abstract}
Bioturbation by terrestrial animals is common in arid and semi-arid continental environments. Scorpions have comprised a significant portion of the diversity of predatory arthropods in these environments from the Late Paleozoic to the Recent. Many scorpions are active burrowers and likely have a substantial, if rarely recognized, ichnofossil record. This project involved the study of the burrowing behaviors and trace morphologies of the scorpion Hadrurus arizonensis (Scorpiones: Caraboctonidae). Individual animals were placed into sediment-filled terrariums for two- to three-week periods after which burrows were cast, excavated, and described. Descriptions of the subsurface structures included architecture, dimensions, bioglyphs, complexity, and tortuosity. Additional experiments were run with differing sediment composition, density, and moisture to evaluate the animal's behavioral response to altering environmental conditions. Specimens of $H$. arizonensis burrowed by scratching and kicking loose sediment from the subsurface with the first two to three pairs of walking legs. The subsurface biogenic structures produced consisted of subvertical ramps, U-shaped burrows, helical burrows, and mazeworks. In the process of excavating the burrows, the desert scorpions also produced a hummocky surface topography as well as structures in dry, sandy sediment that resembled lamination and ripple cross-lamination. Increasing clay content and sediment density increased the complexity of burrow architectures produced. Reducing these variables limited the complexity of the burrows, reduced their likelihood of preservation, and increased the abundance of biogenic cross-lamination. Data collected from these and similar experimental studies can be applied to terrestrial ichnofossil assemblages in order to better interpret the paleoecology of ancient soil ecosystems.
\end{abstract}

Daniel I. Hembree. Department of Geological Sciences, Ohio University, 316 Clippinger Laboratories, Athens, Ohio, 45701, hembree@ohio.edu

Lee M. Johnson. Department of Geological Sciences, Ohio University, 316 Clippinger Laboratories, Athens, Ohio, 45701, USA lj395707@ohio.edu

Robert W. Tenwalde. Department of Geological Sciences, Ohio University, 316 Clippinger Laboratories, Athens, Ohio, 45701, USA rt257007@ohio.edu

Keywords: ichnofossils; trace fossils; bioturbation; continental; arthropod; paleoecology

PE Article Number: 15.1.10A

Copyright: Paleontological Society March 2012

Submission: 22 July 2011. Acceptance: 6 February 2012

Hembree, Daniel I., Johnson, Lee M., Tenwalde, and Robert W. 2012. Neoichnology of the desert scorpion Hadrurus arizonensis: burrows to biogenic cross lamination. Palaeontologia Electronica Vol. 15, Issue 1;10A,34p; palaeo-electronica.org/content/2012-issue-1-articles/192-neoichnology-of-scorpions 


\section{INTRODUCTION}

The purpose of this paper is to document the diverse biogenic structures produced by a species of burrowing scorpion, Hadrurus arizonensis (Arthropoda: Scorpiones), through basic experimental procedures in a controlled laboratory setting. This paper describes the architectural and surficial morphologies of three-dimensional burrows produced by $H$. arizonensis as well as biogenic cross lamination produced as a result of their burrowing methods. The trace morphologies are then linked to scorpion behavior and morphology as well as specific environmental conditions including soil composition, density, and moisture content. The goal of this research is to aid in the recognition of scorpion burrows in the fossil record and to determine if aspects of paleoenvironment can be ascertained by variations in scorpion burrow morphology.

The interpretation of trace fossils, their tracemakers, the behaviors involved in their production, and the environments that influenced their production requires the study of modern organisms. Actualistic studies provide the data that makes trace fossils invaluable to paleoecological and paleoenvironmental reconstructions. Experimental work with trace-making organisms has primarily involved nearshore, marine invertebrates (Frey, 1968, 1970; Ekdale and Berger, 1978; Gregory et al., 1979; Frey et al., 1984, 1987; Pemberton and Frey, 1985; Gaillard, 1991; Kanazawa, 1992; Alexander et al., 1993; Seilacher and Seilacher, 1994; Gingras et al., 2002, 2004; Curran and Martin, 2003; De, 2005; Needham et al., 2005; Martin, 2006; Uchman and Pervesler, 2006; Seike and Nara, 2007; Hertweck et al., 2007; Pearson et al., 2007; Dashtgard et al., 2008). Recently, however, the volume of work on continental organisms has also increased, especially studies involving soil invertebrates (Ahlbrandt et al., 1978; Ratcliffe and Fagerstrom, 1980; Hasiotis and Mitchell, 1993; O'Geen and Busacca, 2001; Deocampo, 2002; Tschinkel, 2003; Gobetz, 2005; Hembree and Hasiotis, 2006, 2007; Lawfield and Pickerill, 2006; Davis et al., 2007; Gingras et al., 2007; Rodriguez-Tovar, 2007; Scott et al., 2007; Smith and Hasiotis, 2008; Counts and Hasiotis, 2009; Hembree, 2009; Halfen and Hasiotis, 2010). The goal of this type of research is to evaluate the trace-making behaviors and the resulting trace morphologies of modern continental burrowing organisms in order to tie these morphologies to specific taxa, body morphologies, behaviors, and environmental conditions. These data can then be used to better interpret the paleobiological, paleoecological, and paleoenvironmental significance of continental ichnofossils. There is a need for greater understanding of continental ichnofossils because they have a wide range of potential uses in paleontological, sedimentological, and sequence stratigraphic studies. In addition, modern soils contain a diverse and abundant biota, including members of all terrestrial phyla. Most of these modern groups, however, are poorly understood taxonomically and ecologically. The fact that these organisms produce burrows in soils is known, but the morphology of the burrows and how the environmental conditions of the soil (soil type, temperature, soil moisture, precipitation) affect the morphology of the burrows is not understood. In addition, it is unclear if the morphologies of burrows produced by organisms within a single taxonomic group are different, and if so to what degree. For example, do all burrowing scorpions produce burrows with the same architecture, and do they all burrow using the same methods while engaged in the same behaviors?

Scorpions represent one the oldest groups of fully terrestrial animals (Petrunkevitch, 1955; Kjellesvig-Wearing, 1986; Sissom, 1990). Scorpions are arthropod predators that inhabit a wide range of environments and climates from tropical rainforests to arid deserts (Polis, 1990). Body fossils of scorpions assigned to the Order Scorpiones have been found in rocks as old as the Silurian (444-416 Ma) although these mostly represent ancestral aquatic forms (Petrunkevitch, 1955; Kjellesvig-Wearing, 1986). Based on numerous complete fossils, scorpions were abundant in terrestrial environments by at least the Mississippian (Petrunkevitch, 1955; Kjellesvig-Wearing, 1986; Sissom, 1990). Body fossils of terrestrial scorpions very similar morphologically to the extant superfamily Scorpionoidea are known from Carboniferous deposits ( 340 Ma) (Petrunkevitch, 1955; Kjellesvig-Wearing, 1986; Jeram, 1994a, 1994b). Some of these species reached very large sizes compared to a few modern species that may reach 10-12 cm in length (Sissom, 1990). Complete body fossils from the Carboniferous of Scotland indicate that some scorpions reached $35-40 \mathrm{~cm}$ in length, and some fossil fragments suggest the presence of scorpions as long as $70 \mathrm{~cm}$ (Jeram, 1994a). There are currently 111 recognized fossil species of scorpions, with the majority from the Paleozoic (79), and lesser amounts from the Mesozoic (16) and Cenozoic (16) (Dunlop et al., 2008).

Because trace fossils are easily preserved in environments where body fossils are rare, the 

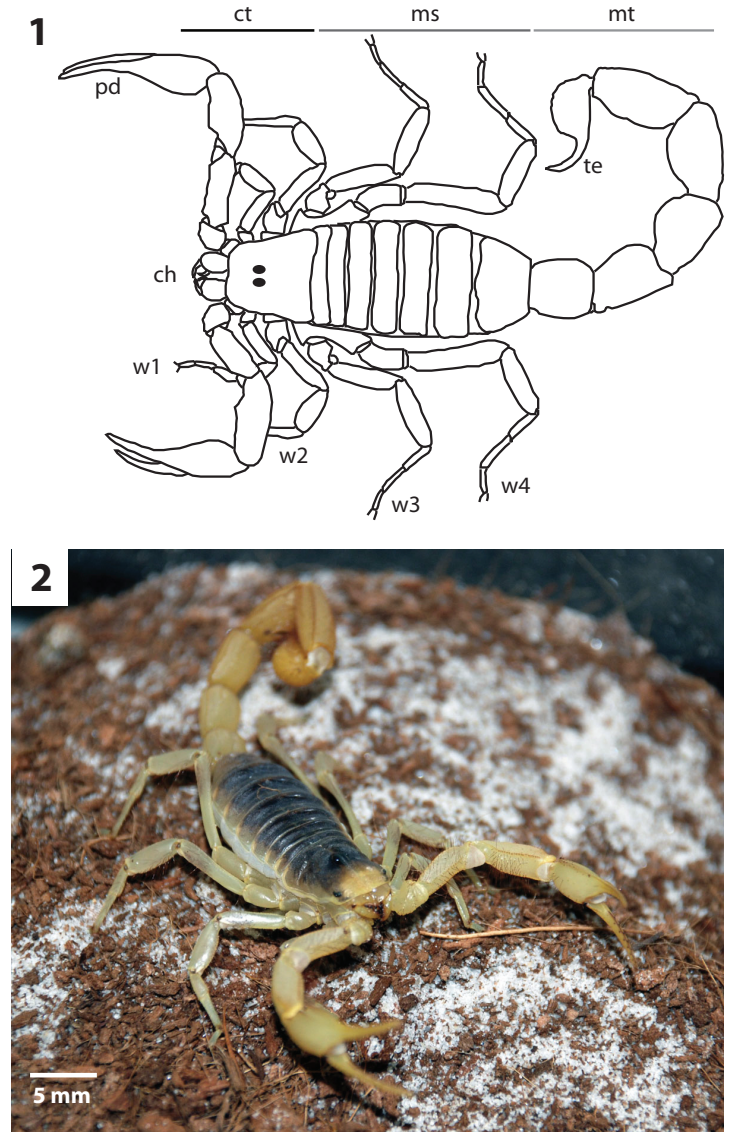

3

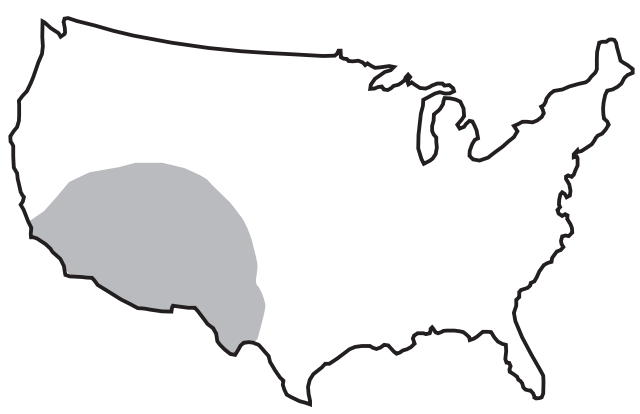

FIGURE 1. 1) General scorpion morphology. ct: cephalothorax; ms: mesosoma; mt: metasoma; pd: pedipalp; ch: chelicerae; te: telson; w1-4: walking legs. 2) Specimen of Hadrurus arizonensis used in this study. 3) Known $H$. arizonensis distribution in the United States.

combination of studies of both body and trace fossils are required to provide a more accurate assessment of the evolutionary and biogeographic history of the group (e.g., Häntzschel, 1975; Osgood, 1975; Bromley, 1996; Pemberton et al., 2001; Hasiotis, 2003). Previously described trace fossils definitively attributed to scorpions are limited and have only included tracks and trails (Brady, 1947; Picard, 1977). One of the primary reasons for the paucity of fossil data may be the lack of well-documented studies of the burrows produced by extant burrowing scorpions.

Few definitive descriptions of scorpion-produced burrows in the modern have been presented in the literature (Williams, 1966; Harrington, 1978; Shorthouse and Marples, 1980; Polis et al., 1986). A major shortcoming of previously published studies, with respect to trace fossil research, is a lack of investigation of the full range of burrow morphologies and burrowing methods, as well as the impact of environmental conditions on burrow architecture. In addition, while some studies may provide idealized diagrams or illustration of burrow architectures, three-dimensional casts are either not produced or not reported.

\section{SCORPION ECOLOGY AND BEHAVIOR}

Scorpions (Class Arachnida) are a diverse group of terrestrial arthropods consisting of over 1700 described extant species within 13 families (Sissom, 1990). The morphology of scorpions is characterized by eight legs, a pair of grasping claws or pedipalps, and a narrow, segmented tail ending in a venomous barb (Hjelle, 1990) (Figure 1.1). The body of a scorpion can be divided into three parts, the cephalothorax (head), mesosoma (abdomen), and metasoma (tail) (Hjelle, 1990). The cephalothorax consists of the carapace, eyes, chelicerae, pedipalps, and four pairs of walking legs. The pedipalps are used for prey immobilization, defense, and sensory purposes. The mesosoma consists of seven segments each covered by a sclerotosed plate. Segments 3-7 have a pair of spiracles which are the openings for the book lungs. The metasoma consists of five segments and a sixth that bears the telson (sting). Modern scorpions are very similar to Paleozoic scorpions; despite changes in locomotion and respiration needed for the move from aquatic to terrestrial habitats, the basic scorpion body plan has been unchanged in 425 million years (Sissom, 1990). Neither is there much difference in external morphology among modern and fossil scorpions from different habitats; scorpions from tropical rainforests are similar to those from deserts (Hjelle, 1990; Sissom, 1990).

Scorpions are present on all continents with the exception of Antarctica and inhabit a wide range of environments and climates including high elevation mountains, arid deserts, tropical rainforests, intertidal zones, and caves (Sissom, 1990). Most scorpions prefer temperatures from $20-37^{\circ}$ $\mathrm{C}$, although some can survive extremes from $-31^{\circ}$ 
C up to $50^{\circ} \mathrm{C}$ (Hadley, 1990). Scorpions are nocturnal and fossorial, hiding in burrows, under rocks, in leaf litter, or under tree bark during the day to avoid detection by predators (Polis, 1990). Scorpions are opportunistic predators of small arthropods and insects, although larger species will hunt small reptiles and mammals (McCormick and Polis, 1990). In terms of density, diversity, and biomass, scorpions are one of the most important and successful predators in many modern habitats (Polis, 1990; McCormick and Polis, 1990). Scorpions have a very low metabolic rate, and some species may survive for up to a year without food while others can live indefinitely without water obtaining all of their required moisture from prey animals (Polis, 1990; Lighton et al., 2001). In general, scorpions have a long lifespan compared to other arthropods, up to 25 years in some species (Polis and Sissom, 1990). While most scorpions are solitary, some are communal and all female scorpions show some degree of maternal care with the young remaining with their mothers for up to several months after hatching (Polis and Sissom, 1990).

All modern scorpion populations are characterized by low levels of surface activity while burrowing scorpions spend the majority of their lives in their burrows (Hadley and Williams, 1968; Tourtlotte, 1974; Polis, 1980; Bradley, 1982; Warburg and Polis, 1990). Obligate fossorial scorpions, which represent an extreme end member of the group, spend all of their lives in their burrows with the exception of time spent in courtship, mating, and the dispersal of newborn (Williams, 1966; Koch, 1978; Shachak and Brand, 1983). But even burrowing scorpions that actively hunt on the surface spend most of their time below the surface. Many scorpions only hunt $20-50 \%$ of all possible nights and are only on the surface for an average of 4 hours (Hadley and Williams, 1968; Tourtlotte, 1974; Polis, 1980; Bradley, 1982; Polis, 1990). This amounts to $90-95 \%$ of their existence spent within their burrows (Polis, 1990). This aspect of scorpion behavior highlights the importance of burrows to their ecology and evolutionary history.

The majority of burrowing scorpions stay within $1 \mathrm{~m}$ of their burrow entrance when on the surface (Polis, 1990) although individuals may forage at greater distances, up to $8 \mathrm{~m}$ in extreme examples (Polis et al., 1986). Some species will return to previously constructed burrows even after traveling relatively large distances suggesting that some are capable of homing, but the exact mechanism for this behavior is not well understood (Polis, 1990). The value of homing behaviors is under- standable and considerable selective pressure would have favored its evolution in scorpions. For example, with such low metabolic rates, burrow construction is energetically costly to scorpions especially for those that are ambush predators and are stationary most of the time (Polis, 1990; White, 2001). Some scorpions may excavate 200-400 times their body weight in sediment during burrow construction (Shorthouse and Marples, 1980).

Burrows provide scorpions a refuge from predators and from potentially harmful surface conditions such as extreme temperatures and humidity (Newlands, 1969; Polis, 1990). Extreme temperatures $\left(35+^{\circ} \mathrm{C}\right)$ are moderated only $5 \mathrm{~cm}$ below the surface, relative humidity is much higher, and rates of exapotranspiration are much lower (Polis, 1990). The burrow is used for almost all of the scorpion's life activities including birth, maternal care, molting, feeding, and in some species mating (Polis, 1990). Burrows also provide a protective environment for the time after molting; burrowing scorpions will in fact only molt within a burrow (Polis, 1990). While many burrowing scorpions forage away from the entrance of their burrows, the remains of prey animals within burrows suggests that even those that forage on the surface carry prey back to the burrow for feeding (McCormick and Polis, 1990).

Different scorpion species use a combination of chelae, chelicerae, legs, and even the tail to loosen and remove soil and to compact burrow walls (Williams, 1966; Eastwood, 1978; Harrington, 1978; Koch, 1978; Shorthouse and Marples, 1980; Polis et al., 1986; Polis, 1990; Rutin, 1996; White, 2001). These anatomical structures are typically adapted to specific substrate characteristics such as hardness and particle size (Polis, 1990). Studies of some scorpions have shown that those that inhabit hard soils have short but stout legs, setae, and chelicerae while those in looser soils have thinner and longer structures (Lamoral, 1979). Field studies have shown that scorpions construct an array of burrow types. Some consistently use the burrows of other animals such as spiders or rodents (Koch, 1978). Simple burrows are enlarged natural openings beneath rocks or logs which may be horizontal to or perpendicular to the surface (Polis, 1990). Most scorpion burrows are constructed at a $20-40^{\circ}$ angle to the surface and are often relatively straight or slightly curved (Williams, 1966; Shorthouse and Marples, 1980; Polis et al., 1986). Burrows of some species may form loose spirals as they descend (Koch, 1978; Shorthouse and Marples, 1980; Polis et al., 1986; White, 2001). Some burrows may contain enlarged chambers at 
the entrance or terminus (Polis, 1990). The burrows may have two or more entrances or tunnels, and the entryways are oval in cross section, wider than they are high (Polis, 1990). The burrow entrances are typically flat on the bottom and crescent-shaped on top conforming to the cross-sectional shape of the scorpion's body (Polis, 1990). Most scorpion burrows are 15-50 cm deep, although some Hadrurus specimens have been found up to $2 \mathrm{~m}$ deep (Stahnke, 1966; Polis, 1990). The depth of the burrow appears to be a function of the age and sex of the scorpion; younger age groups and males construct shallower burrows than adult females (Polis, 1990). Some studies have also shown that burrow depth varies in relation to average rainfall, where burrows are deeper in arid regions than in wetter regions (Koch, 1978).

Hadrurus arizonensis, commonly referred to as the giant desert hairy scorpion, is one of nine species of the genus Hadrurus and the largest extant scorpion in North America reaching up to 14 $\mathrm{cm}$ in length (Hjelle, 1990) (Figure 1.2). Hadrurus arizonensis is characterized by two long and narrow pedipalps and brown setae ("hairs") that cover its body which allow the scorpion to detect vibrations in the soil (Hjelle, 1990). They are solitary animals and like most other scorpions, $H$. arizonensis is a nocturnal predator (Bub and Bowerman, 1979). The large size of $H$. arizonensis allows it to feed on a variety of invertebrates including other scorpions as well as small vertebrates such as rodents, lizards, and snakes (Bub and Bowerman, 1979). They inhabit regions with semi-arid to arid climates with semi-arid to arid climates and are especially adapted to hot and dry conditions (Hadley, 1970a, 1974, 1990). In the United States, $H$. arizonensis is distributed throughout the Sonora and Mojave deserts (Sissom, 1990) (Figure 1.3). They are usually found in low elevation valleys where they construct burrows that can be up to 2.5 $m$ deep although there has been limited research on how these burrows are constructed or the details of their morphology (Hadley, 1970b; Bub and Bowerman, 1979; Tallarovic et al., 2000).

\section{MATERIAL AND METHODS}

Eight specimens of $H$. arizonensis were acquired from a commercial source for use in this study. The specimens were all mature adults that averaged $110 \mathrm{~mm}$ in length $(100-130 \mathrm{~mm}$, $\mathrm{SD}=10.7)$ and $35 \mathrm{~mm}$ in width $(30-40 \mathrm{~mm}$, $S D=3.8)$. The scorpions were kept in the laboratory for one month before the experiments were conducted to allow them to acclimate to the new condi- tions. During that time they were housed individually within 10 gallon aquariums filled with $20 \mathrm{~cm}$ of sandy soil. A temperature range of 25$30^{\circ} \mathrm{C}$ and humidity of $20-30 \%$ was maintained for the enclosures as well as a 12 hour light-dark cycle for the laboratory. The scorpions were fed live crickets once per week and handled as little as possible during the acclimation period. These environmental parameters were maintained throughout the experimental phase as well.

Twenty-seven different burrowing experimental setups were used with the specimens of $H$. arizonensis (Table 1). These experiments were designed in order to (1) observe the burrowing methods of $H$. arizonensis, (2) to document the surface features produced during the occupation of the test enclosures, (3) to observe the behaviors associated with the burrows, and (4) to document the basic burrow morphologies by producing threedimensional casts once the scorpions had been removed.

The specimens were placed in sediment-filled $10(51 \mathrm{~L} \times 27 \mathrm{~W} \times 32 \mathrm{H} \mathrm{cm}), 20(62 \mathrm{~L} \times 32 \mathrm{~W} \times 43 \mathrm{H}$ $\mathrm{cm})$, and $56(76 \mathrm{~L} \times 46 \mathrm{~W} \times 64 \mathrm{H} \mathrm{cm})$ gallon aquaria. The tanks were filled with 20,35 , and $55 \mathrm{~cm}$ of sediment, respectively. These sediment depths allowed enough open space beneath the aquarium cover $(\sim 10 \mathrm{~cm})$ to allow the placement of a water dish, rock, and other hides as well as to prevent escape. The three different sizes of enclosures were used to determine if size constraints affected the morphology of the burrows produced by the scorpions. The scorpions were exposed to varying environmental parameters including soil composition, soil density, and soil moisture. The sediment used to fill the experimental enclosures was characterized by varying concentrations of clay- and fine to medium sand-sized particles that controlled the bulk density of the medium. Sediment with a low bulk density was composed of $75 \%$ sand and $25 \%$ clay. Sediment with a moderate bulk density was composed of $50 \%$ sand and $50 \%$ clay. Sediment with a high bulk density was composed of $25 \%$ sand and $75 \%$ clay. The sediment was thoroughly mixed, and water was added prior to filling the experimental enclosures. The sediment was then added to the enclosure and mixed so that it had a homogenous texture. The sediment was compressed as it was added in order to increase density when needed. The density and moisture of the sediment in each enclosure were quantified using a Field Scout SC900 Soil Compaction Meter (Spectrum Technologies Inc.) and an Aquaterr EC300 Salinity Multimeter, respectively. Measure- 
TABLE 1. Experimental parameters and resulting burrow morphologies. SR: subvertical ramp, UB: U-shaped burrow, HB: helical burrow, MW: mazework, XL: cross lamination. Sediment density values are in $\mathrm{kgf} / \mathrm{cm}^{2}$. Sediment depths are in $\mathrm{cm}$. Sediment moisture values are in percent total volume.

\begin{tabular}{|c|c|c|c|c|c|}
\hline Tank Size & Sediment Composition & $\begin{array}{l}\text { Sediment } \\
\text { Depth }\end{array}$ & $\begin{array}{c}\text { Sediment } \\
\text { Density }\end{array}$ & $\begin{array}{l}\text { Sediment } \\
\text { Moisture }\end{array}$ & $\begin{array}{c}\text { Burrow } \\
\text { Architecture }\end{array}$ \\
\hline 10 & $75-25 \%$ clay-sand & 20 & $2.1-3.2$ & 0 & None \\
\hline 10 & $50-50 \%$ clay-sand & 20 & $1.1-1.4$ & 0 & None \\
\hline 10 & $25-75 \%$ clay-sand & 20 & $0.4-0.7$ & 0 & $X L$ \\
\hline 10 & $75-25 \%$ clay-sand & 20 & $2.1-3.2$ & 20 & $\mathrm{SR}, \mathrm{UB}, \mathrm{HB}, \mathrm{MW}$ \\
\hline 10 & $50-50 \%$ clay-sand & 20 & $1.1-1.4$ & 20 & SR, UB \\
\hline 10 & $25-75 \%$ clay-sand & 20 & $0.4-0.7$ & 20 & $\mathrm{SR}$ \\
\hline 10 & $75-25 \%$ clay-sand & 20 & $2.1-3.2$ & 50 & $\mathrm{SR}, \mathrm{UB}, \mathrm{HB}, \mathrm{MW}$ \\
\hline 10 & $50-50 \%$ clay-sand & 20 & $1.1-1.4$ & 50 & $\mathrm{SR}, \mathrm{UB}$ \\
\hline 10 & $25-75 \%$ clay-sand & 20 & $0.4-0.7$ & 50 & $\mathrm{SR}$ \\
\hline 20 & $75-25 \%$ clay-sand & 35 & $2.1-3.2$ & 0 & None \\
\hline 20 & $50-50 \%$ clay-sand & 35 & $1.1-1.4$ & 0 & None \\
\hline 20 & $25-75 \%$ clay-sand & 35 & $0.4-0.7$ & 0 & $X L$ \\
\hline 20 & $75-25 \%$ clay-sand & 35 & $2.1-3.2$ & 20 & $\mathrm{SR}, \mathrm{UB}, \mathrm{HB}, \mathrm{MW}$ \\
\hline 20 & $50-50 \%$ clay-sand & 35 & $1.1-1.4$ & 20 & SR, UB \\
\hline 20 & $25-75 \%$ clay-sand & 35 & $0.4-0.7$ & 20 & $S R$ \\
\hline 20 & $75-25 \%$ clay-sand & 35 & $2.1-3.2$ & 50 & $\mathrm{SR}, \mathrm{UB}, \mathrm{HB}, \mathrm{MW}$ \\
\hline 20 & $50-50 \%$ clay-sand & 35 & $1.1-1.4$ & 50 & SR, UB \\
\hline 20 & $25-75 \%$ clay-sand & 35 & $0.4-0.7$ & 50 & SR \\
\hline 56 & $75-25 \%$ clay-sand & 55 & $2.1-3.2$ & 0 & None \\
\hline 56 & $50-50 \%$ clay-sand & 55 & $1.1-1.4$ & 0 & None \\
\hline 56 & $25-75 \%$ clay-sand & 55 & $0.4-0.7$ & 0 & $X L$ \\
\hline 56 & $75-25 \%$ clay-sand & 55 & $2.1-3.2$ & 20 & $\mathrm{SR}, \mathrm{UB}, \mathrm{HB}, \mathrm{MW}$ \\
\hline 56 & $50-50 \%$ clay-sand & 55 & $1.1-1.4$ & 20 & SR, UB \\
\hline 56 & $25-75 \%$ clay-sand & 55 & $0.4-0.7$ & 20 & $\mathrm{SR}$ \\
\hline 56 & $75-25 \%$ clay-sand & 55 & $2.1-3.2$ & 50 & $\mathrm{SR}, \mathrm{UB}, \mathrm{HB}, \mathrm{MW}$ \\
\hline 56 & $50-50 \%$ clay-sand & 55 & $1.1-1.4$ & 50 & $\mathrm{SR}, \mathrm{UB}$ \\
\hline 56 & $25-75 \%$ clay-sand & 55 & $0.4-0.7$ & 50 & $\mathrm{SR}$ \\
\hline
\end{tabular}

ments for both sediment density and moisture were taken every $10 \mathrm{~cm}$ to ensure that the sediment properties were homogenous. The density of each type of sediment was characterized as low with soil resistance of $0.4-0.7 \mathrm{kgf} / \mathrm{cm}^{2}$, moderate with a soil resistance of $1.1-1.4 \mathrm{kgf} / \mathrm{cm}^{2}$, and high with soil resistance of $2.1-3.2 \mathrm{kgf} / \mathrm{cm}^{2}$. Soil moisture was set to 0,20 , and $50 \% 20 \mathrm{~cm}$ below the surface by adding predetermined quantities of water to the sediment mixture when the aquaria were filled. Soil moisture was maintained by spraying the surface of the tank twice per week with 0,100 , and $200 \mathrm{~mL}$ of water, respectively.

Each experiment commenced with the placement of a single scorpion into an experimental enclosure. The scorpions were left in the enclosures for periods of 14 and 21 days before removing the specimens. The two different time intervals 


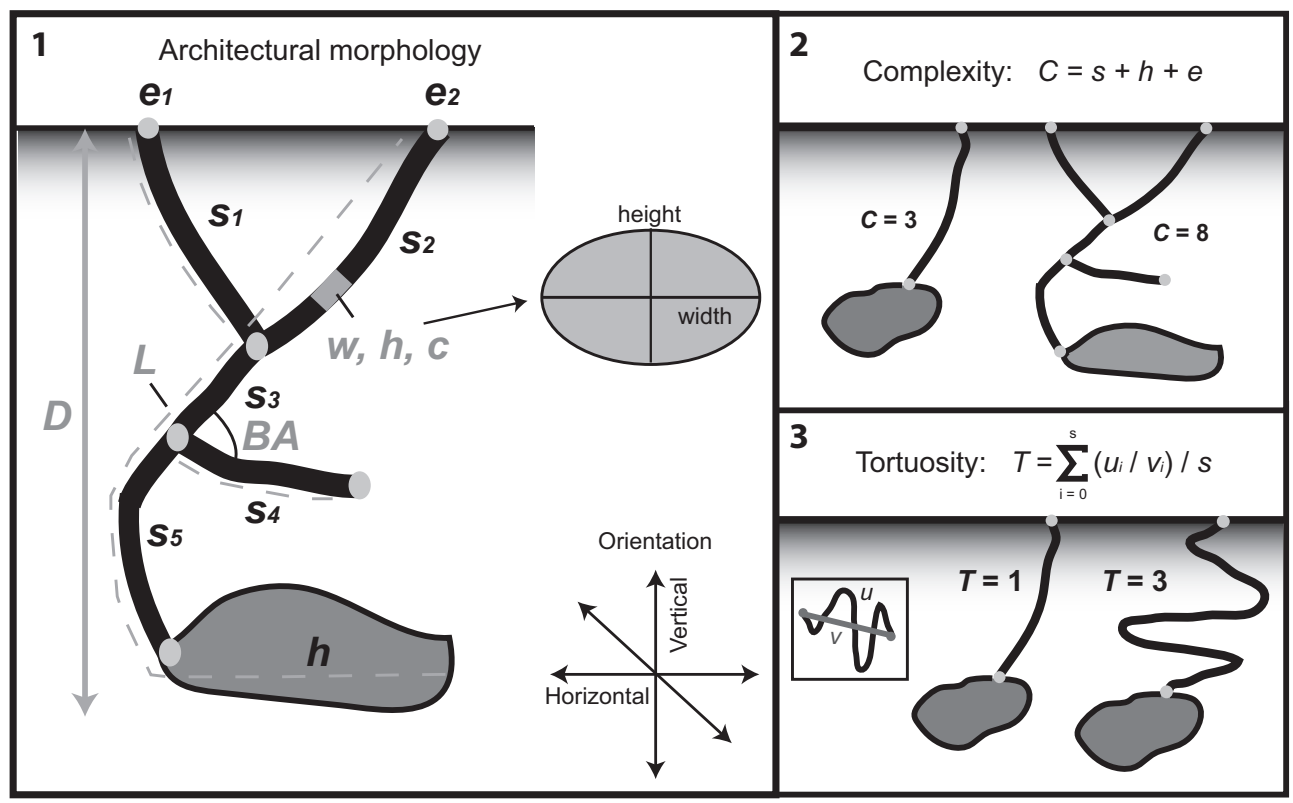

FIGURE 2. Quantitative burrow description models. 1) Burrows were described by their maximum depth (D), tunnel and shaft width (w), height (h), and circumference (c), total length (L), and branching angle (BA). Burrows were divided into segments (s), surface openings (e), and chambers (h). 2) Complexity is a measure of the number of segments, chambers, and surface openings (e) within a single burrow system. 3) Tortuosity is a measure of the average sinuosity of all of the segments of a burrow system. The tortuosity of a single segment is found by dividing the total length $(u)$ by the straight line distance $(v)$.

were used to examine the changes in burrow morphology over time. The scorpions were observed and filmed using a digital camcorder as they burrowed. The observations included the time that elapsed before the scorpion began burrowing, the burrowing methods used, and the time needed for the animal to completely burrow into the sediment. Once the burrow was completed, daily observations were then conducted, documenting the excavation of new burrows, destruction of old burrows and the scorpion behaviors directly associated with the burrows. At the end of each experimental period, the scorpions were captured when they were on the surface foraging at night. If the scorpion did not construct a burrow by the end of the experimental period, this was noted and all surface features were documented before the animal was removed. Once the specimens were removed from the enclosures, the open burrows were filled with Drystone $®$ plaster, excavated, and described.

Descriptions of the three dimensional burrow casts included qualitative and quantitative aspects of their architectural and surficial morphologies (Figure 2). Architectural morphology is defined by the burrow's general appearance, dimensions, cross-sectional shape of shafts and tunnels, orientation in the sediment, type and amount of branch- ing, and degree of interconnectedness of different burrow elements. The surficial morphology includes the minute structures (scratches, bumps, linings) on the burrow walls that record the methods of excavation used in construction and maintenance of the burrow, as well as the type of locomotion used by the animal while it inhabited the burrow. For each burrow cast produced in these experiments, eight quantitative measurements of burrow morphology were recorded: 1) maximum depth (D); 2) total length (L); 3) tunnel or shaft width $(\mathrm{w})$ measured every $1 \mathrm{~cm} ; 4)$ tunnel or shaft height $(\mathrm{h})$ measured every $1 \mathrm{~cm} ; 5)$ ratio of cross-sectional width to height; 6 ) tunnel or shaft circumference (c) measured every $1 \mathrm{~cm} ; 7$ ) angle of shafts or tunnel with respect to the horizontal; and 8) angle of branching (BA) if present (Figure 2.1). Total burrow length is the sum of the length of all of the shafts, tunnels, and chambers. The crosssectional width to height ratio was determined from an average of five tunnel cross sections. Angle of branching was measured between intersecting burrows away from the walls of the enclosures. Maximum depth to the bottom of a burrow was measured from a surface opening to the base of the deepest tunnel; for those burrows that reached 
the base of the enclosure, this value was used as a minimum estimate.

Burrow complexity and tortuosity are two additional quantitative descriptions of burrow morphology. The complexity and tortuosity are independent of scale and are used to differentiate burrow systems produced by animals of different sizes (e.g., Meadows 1991). Burrow complexity $(C)$ is a measure of the number of different tunnels, shafts, openings, and chambers that are present in a burrow system (Figure 2.2). Burrow complexity is a function of: 1) the number of segments (s)defined as non-branching lengths of a burrow; 2) the number of openings to the soil surface (e); and 3 ) the number of chambers $(h)$-defined as areas with a greater cross-sectional area than the segments. These measurements define an index of complexity $(C)$ that is calculated by $C=s+h+e$, where $C \geq 1$. The tortuosity $(T)$ of a burrow system is a measure of the deviation of the tunnels from a straight line (Figure 2.3). The tortuosity of an open segment is calculated by dividing the total length of the segment $(u)$ by the straight-line distance between the ends of the segment $(v)$. The tortuosity index of the entire burrow system will be determined by calculating the average tortuosity of all of the burrow segments.

The quantitative aspects of the burrow morphology were used to determine the level of similarity of burrows produced by specimens of $H$. arizonensis, the effects of sediment density on burrow morphology, as well as the level of similarity to burrows produced by the emperor scorpion (Pandinus imperator) and a species of whip scorpion (Mastigoproctus giganteus) produced in separate laboratory experiments. Individual burrows were compared using a Bray Curtis Similarity measure, which is a nonparametric statistical analysis used to determine the level of similarity between multiple samples with multiple quantitative properties (Hammer and Harper, 2006). Ten quantitative values were used to compare the different burrow casts including the number of surface openings, maximum depth, total length, average width, average height, width:height ratio, average circumference, average slope, complexity, and tortuosity. The level of similarity is ranked from 0 to 1,0 indicating completely different samples, and 1 indicating identical samples. In this analysis, values from 0.9-0.8 were interpreted as indicating a high degree of similarity, $0.7-0.6$ were interpreted as indicating a moderate degree of similarity, and values $\leq 0.5$ were interpreted as indicating dissimilarity. The Bray Curtis Similarity measure was used in this study because it analyzes all aspects of the burrow's morphology at once, rather than comparing one feature such as diameter, length, or volume. The architecture of a burrow is a sum of many parts; while burrows of several different animals may have the same diameter, length, or volume, it is less likely that all three components of their morphology are the same. The Bray Curtis Similarity measure allows these differences to be ascertained quickly. Burrows produced by $\mathrm{H}$. arizonensis in sediment with different bulk densities (low, moderate, high) were evaluated using Spearman's rank correlation, a nonparametric technique used to determine if two variables vary together (Hammer and Harper, 2006). Sediment density was treated as the independent variable and the different quantitative measurement of burrow morphology including complexity, tortuosity, circumference, total length, maximum width, maximum height, maximum depth, and average slope were treated as the dependent variables. All statistical analyses were performed with Palaeontological Statistics (PAST).

\section{EXPERIMENTAL RESULTS}

Specimens of $H$. arizonensis produced permanent open burrows with varying architectural morphologies in sediment with a moderate and high bulk density (Table 1). Those specimens placed in sediment with a low bulk density produced temporary burrows that collapsed in less than one day and could not be cast. Those specimens placed in sediment with a low bulk density and no moisture, however, did produce distinct cross lamination structures (Table 1). A total of 17 complete and well-preserved burrow casts were produced from the experimental trials (Table 2). Many experiments resulted either in only partial burrow casts or burrows that were destroyed by the scorpions or gravitational collapse before they could be cast. In all experiments, however, the architectural morphology of the burrows in situ was recorded.

\section{Behavior}

Specimens of $H$. arizonensis began burrow construction within $24-48$ hours of placement into the experimental enclosures. In the time before burrowing, the specimens moved around the entire enclosure. In most experiments, one to three burrows were begun but abandoned soon after excavation began, typically in 12-24 hours. These preliminary attempts resulted in shallow, $1-4 \mathrm{~cm}$ deep, pits. Once an individual specimen of $H$. ari- 
TABLE 2. Measurements of representative three dimensional casts of burrows produced by Hadrurus arizonensis (DHS), Pandinus imperator (ES), and Mastigoproctus giganteus (WS). All measurements are in $\mathrm{cm}$.

\begin{tabular}{|c|c|c|c|c|c|c|c|c|c|}
\hline & DHS1 & DHS2 & DHS3 & DHS4 & DHS5 & DHS6 & DHS7 & DHS8 & DHS9 \\
\hline Architecture & $\overline{S R}$ & $\overline{S R}$ & $\overline{H B}$ & MW & MW & SR & HB & MW & UB \\
\hline Surface openings & 1 & 1 & 1 & 5 & 4 & 1 & 1 & 3 & 2 \\
\hline Maximum depth & 3.9 & 2.8 & 7.2 & 7.4 & 6.7 & 4.3 & 4.6 & 8.4 & 8.0 \\
\hline Total length & 11 & 9 & 27 & 57 & 46 & 7 & 13 & 31 & 30 \\
\hline Maximum width & 4.3 & 6.0 & 7.7 & 4.6 & 6.4 & 5.9 & 3.3 & 7.2 & 4.2 \\
\hline Minimum width & 3.2 & 3.0 & 2.8 & 1.9 & 2.6 & 2.9 & 2.7 & 2.9 & 3.0 \\
\hline Average width & 3.9 & 4.8 & 4.5 & 3.6 & 4.2 & 4.2 & 3.1 & 4.7 & 3.6 \\
\hline Maximum height & 2.8 & 1.9 & 3.2 & 2.3 & 3.1 & 1.6 & 1.4 & 2.6 & 2.5 \\
\hline Minimum height & 1.0 & 1.1 & 0.8 & 0.8 & 1.4 & 1.0 & 0.6 & 1.4 & 1.5 \\
\hline Average height & 1.9 & 1.6 & 2.0 & 1.8 & 1.9 & 1.4 & 1.0 & 1.9 & 2.1 \\
\hline Average $\mathrm{W} / \mathrm{H}$ ratio & 2.1 & 3.0 & 2.3 & 2.0 & 2.2 & 3.0 & 3.1 & 2.5 & 1.7 \\
\hline $\begin{array}{l}\text { Maximum } \\
\text { circumference }\end{array}$ & 12.1 & 14.0 & 18.0 & 14.5 & 17.0 & 11.5 & 10.5 & 16.0 & 11.5 \\
\hline Minimum circumference & 10.0 & 11.2 & 6.5 & 9.5 & 10.5 & 6.0 & 8.5 & 9.5 & 10.5 \\
\hline Average circumference & 11.2 & 12.7 & 14.5 & 13.1 & 12.2 & 9.4 & 9.0 & 12.3 & 11.3 \\
\hline Maximum slope & $40^{\circ}$ & $10^{\circ}$ & $30^{\circ}$ & $50^{\circ}$ & $90^{\circ}$ & $30^{\circ}$ & $40^{\circ}$ & $50^{\circ}$ & $90^{\circ}$ \\
\hline Minimum slope & $0^{\circ}$ & $0^{\circ}$ & $0^{\circ}$ & $0^{\circ}$ & $0^{\circ}$ & $0^{\circ}$ & $0^{\circ}$ & $0^{\circ}$ & $0^{\circ}$ \\
\hline Average slope & $20^{\circ}$ & $5^{\circ}$ & $15^{\circ}$ & $27^{\circ}$ & $37^{\circ}$ & $15^{\circ}$ & $20^{\circ}$ & $30^{\circ}$ & $45^{\circ}$ \\
\hline Branching angles & NA & NA & NA & 75 & 75 & NA & NA & 70 & NA \\
\hline Complexity & 3 & 3 & 3 & 9 & 9 & 3 & 3 & 7 & 4 \\
\hline Tortuosity & 1.1 & 1.1 & 9.0 & 1.4 & 1.8 & 1.1 & 3.3 & 1.1 & 1.3 \\
\hline Sediment Density & L & L & $\mathrm{H}$ & $\mathrm{H}$ & $\mathrm{H}$ & $\mathrm{L}$ & $\mathrm{H}$ & $\mathrm{H}$ & M \\
\hline
\end{tabular}

zonensis began a final burrow, it was able to complete the excavation of the burrow in 4-6 hours. There was no consistent placement of the burrow entrance within the tank. Burrow openings were located at the edge and center of the enclosures, next to rocks and water dishes, and in the open.
Hadrurus arizonensis was observed to burrow by direct excavation using the first three walking legs to both kick and drag sediment particles to the surface (Figure 3 ). The scorpion initiated burrowing by kicking loose sediment behind its body with the first two pairs of walking legs. These legs were moved rapidly with enough force to move sand- 
TABLE 2 (continued).

\begin{tabular}{|c|c|c|c|c|c|c|c|c|c|c|}
\hline & DHS10 & DHS11 & DHS12 & DHS13 & DHS14 & DHS15 & DHS16 & DHS17 & ES1 & WS1 \\
\hline Architecture & SR & SR & SR & SR & SR & HB & SR & SR & HB & MW \\
\hline Surface openings & 1 & 1 & 1 & 1 & 1 & 1 & 1 & 1 & 1 & 4 \\
\hline Maximum depth & 3.0 & 4.2 & 3.4 & 4.0 & 4.2 & 16.0 & 5.3 & 6.8 & 12.5 & 12.4 \\
\hline Total length & 16 & 11 & 19 & 19 & 23 & 76 & 37 & 26 & 36 & 66 \\
\hline Maximum width & 5.2 & 4.4 & 6.5 & 4.9 & 6.7 & 5.3 & 6.2 & 5.4 & 12.0 & 6.2 \\
\hline Minimum width & 3.8 & 4.1 & 4.2 & 3.1 & 4.1 & 3.7 & 3.1 & 4.0 & 7.9 & 3.7 \\
\hline Average width & 4.4 & 4.3 & 5.2 & 4.1 & 4.9 & 4.5 & 4.8 & 4.9 & 9.7 & 4.6 \\
\hline Maximum height & 2.1 & 2.0 & 3.3 & 2.6 & 2.3 & 3.3 & 2.8 & 2.2 & 5.1 & 2.0 \\
\hline Minimum height & 1.3 & 0.9 & 1.9 & 1.8 & 1.4 & 1.6 & 1.7 & 1.5 & 2.8 & 1.7 \\
\hline Average height & 1.8 & 1.6 & 2.2 & 2.2 & 1.7 & 2.3 & 2.4 & 1.8 & 3.9 & 1.9 \\
\hline Average $\mathrm{W} / \mathrm{H}$ ratio & 2.4 & 2.7 & 2.4 & 1.9 & 2.9 & 2.0 & 2.0 & 2.7 & 2.5 & 2.4 \\
\hline $\begin{array}{l}\text { Maximum } \\
\text { circumference }\end{array}$ & 13.6 & 11.2 & 16.5 & 13.0 & 15.5 & 14.0 & 15.0 & 13.0 & 27.0 & 14.5 \\
\hline Minimum circumference & 9.7 & 6.8 & 11.5 & 9.9 & 10.5 & 10.0 & 11.0 & 11.5 & 20.5 & 9.0 \\
\hline Average circumference & 11.9 & 10.0 & 13.9 & 11.5 & 12.5 & 17.3 & 12.9 & 12.6 & 23.8 & 11.3 \\
\hline Maximum slope & $10^{\circ}$ & $40^{\circ}$ & $10^{\circ}$ & $20^{\circ}$ & $20^{\circ}$ & $30^{\circ}$ & $20^{\circ}$ & $20^{\circ}$ & $40^{\circ}$ & $80^{\circ}$ \\
\hline Minimum slope & $0^{\circ}$ & $0^{\circ}$ & $0^{\circ}$ & $0^{\circ}$ & $0^{\circ}$ & $0^{\circ}$ & $0^{\circ}$ & $0^{\circ}$ & $0^{\circ}$ & $0^{\circ}$ \\
\hline Average slope & $5^{\circ}$ & $20^{\circ}$ & $5^{\circ}$ & $10^{\circ}$ & $10^{\circ}$ & $13^{\circ}$ & $10^{\circ}$ & $8^{\circ}$ & $20^{\circ}$ & $45^{\circ}$ \\
\hline Branching angles & NA & NA & NA & NA & NA & NA & 65 & NA & NA & 80 \\
\hline Complexity & 3 & 3 & 3 & 3 & 3 & 3 & 4 & 3 & 3 & 10 \\
\hline Tortuosity & 1.3 & 1.5 & 1.1 & 1.2 & 1.4 & 3.3 & 1.4 & 1.2 & 1.7 & 1.4 \\
\hline Sediment Density & M & L & M & M & M & $\mathrm{H}$ & $\mathrm{H}$ & M & NA & NA \\
\hline
\end{tabular}

sized grains $5-15 \mathrm{~cm}$ (Figure 4.1-2). As the scorpion began to form a shallow depression the third pair of walking legs was also used to excavate sediment in a similar manner. The pedipalps were never used to excavate or manipulate the sediment in any way regardless of location within the aquarium. They were raised above the sediment surface and folded back against the scorpion's body while excavating. When large sediment particles were encountered, the scorpion gathered them underneath its body with the walking legs and then dragged them backward out of the excavation area (Figure 4.3). As the excavation moved deeper into the subsurface and the burrow depth increased, the 'gather and drag' method was used more commonly. 

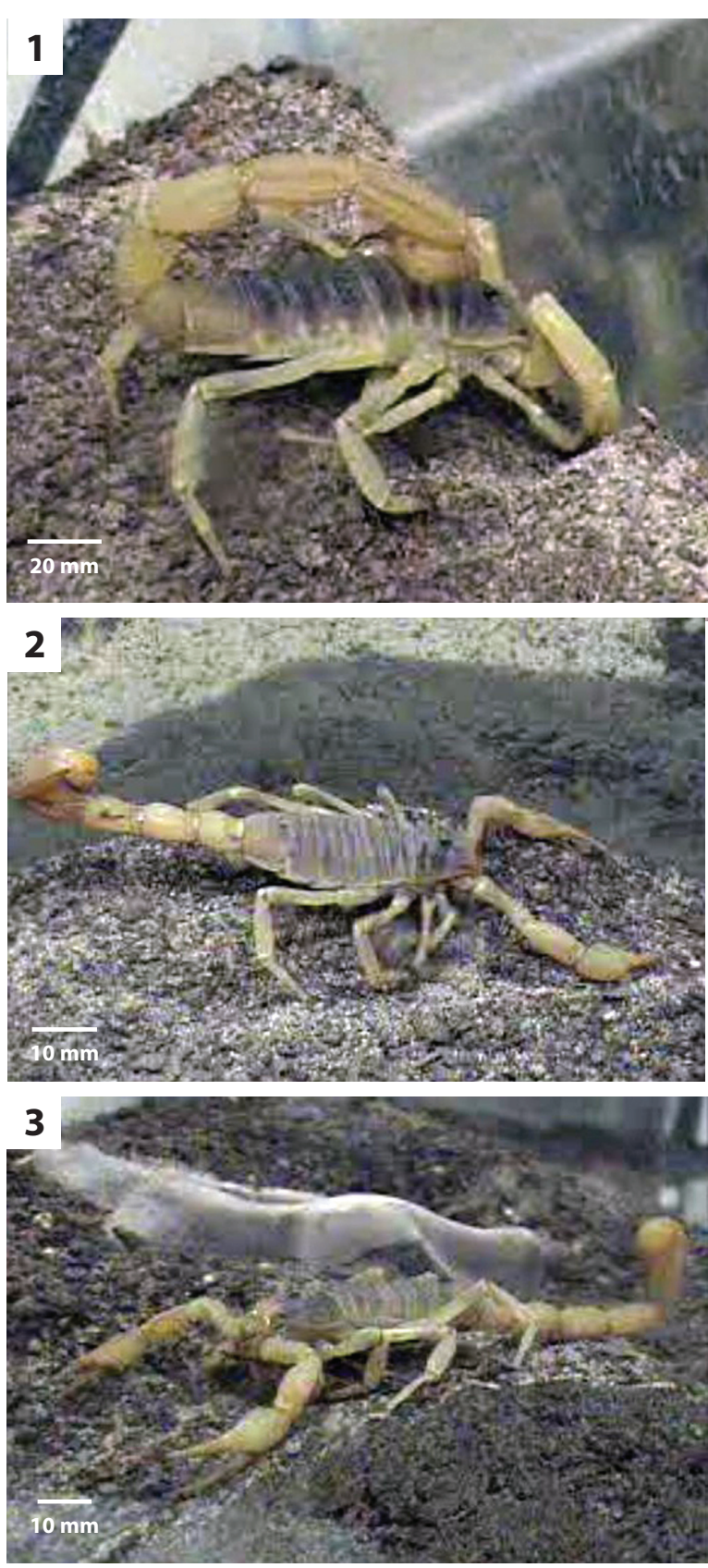

FIGURE 3. Burrowing methods used by $H$. arizonensis. 1) Excavation by kicking sediment behind the body using the first two walking legs. The pedipalps are held up and are not involved in burrowing. 2) Excavation by kicking sediment using the first three walking legs. 3) Excavation by gathering sediment with the first three walking legs and dragging it away from the site of active excavation.

Specimens of $H$. arizonensis constructed open burrows in sediment with low to high bulk density and in sediment with low to moderate soil moisture levels (20 and 50\%) (Table 1). Open bur-

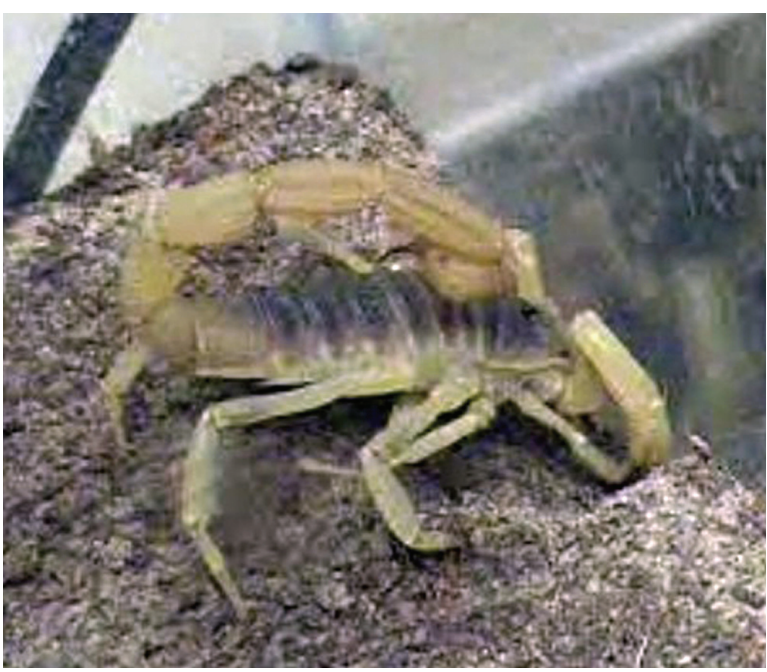

FIGURE 4. Video (see online) of specimens of $\mathrm{H}$. arizonenensis engaged in different burrowing methods.

rows had sharp, irregular walls with no evidence of a constructed lining regardless of the substrate properties or time of occupation. Sediment with no moisture content was too unstable for the scorpions to construct open burrows (Table 1). This was the only experimental substrate, which excluded $H$. arizonensis from the subsurface. The scorpions were able to dig shallow to deep pits $(2-10 \mathrm{~cm}$ deep) in this sediment, however, producing undulating topography and biogenic cross lamination in sediment which also had low bulk density (Table 1 ).

The burrows were used by the scorpions as permanent to temporary dwellings. Permanent dwellings were those that were constructed and maintained throughout the experimental period. The burrows were considered temporary if they were abandoned during the experimental period. The scorpion burrows were observed to be continuously maintained and modified during their occupation. After initial excavation, the burrows were made deeper, terminal chambers were widened, surface openings were reopened or new surface openings were produced after a tunnel collapse, new tunnels were excavated in the subsurface, and in some cases additional surface openings were produced. In some experiments, the original burrows were destroyed and replaced by new burrows. This occurred up to three times in a single experiment. In addition to being used as shelter, the burrows were also used to assist the scorpions in prey capture. Prey animals, primarily crickets, placed into the experimental enclosures would generally enter the burrow openings either immediately or within a few hours. The scorpions were typically positioned just inside the burrow opening 

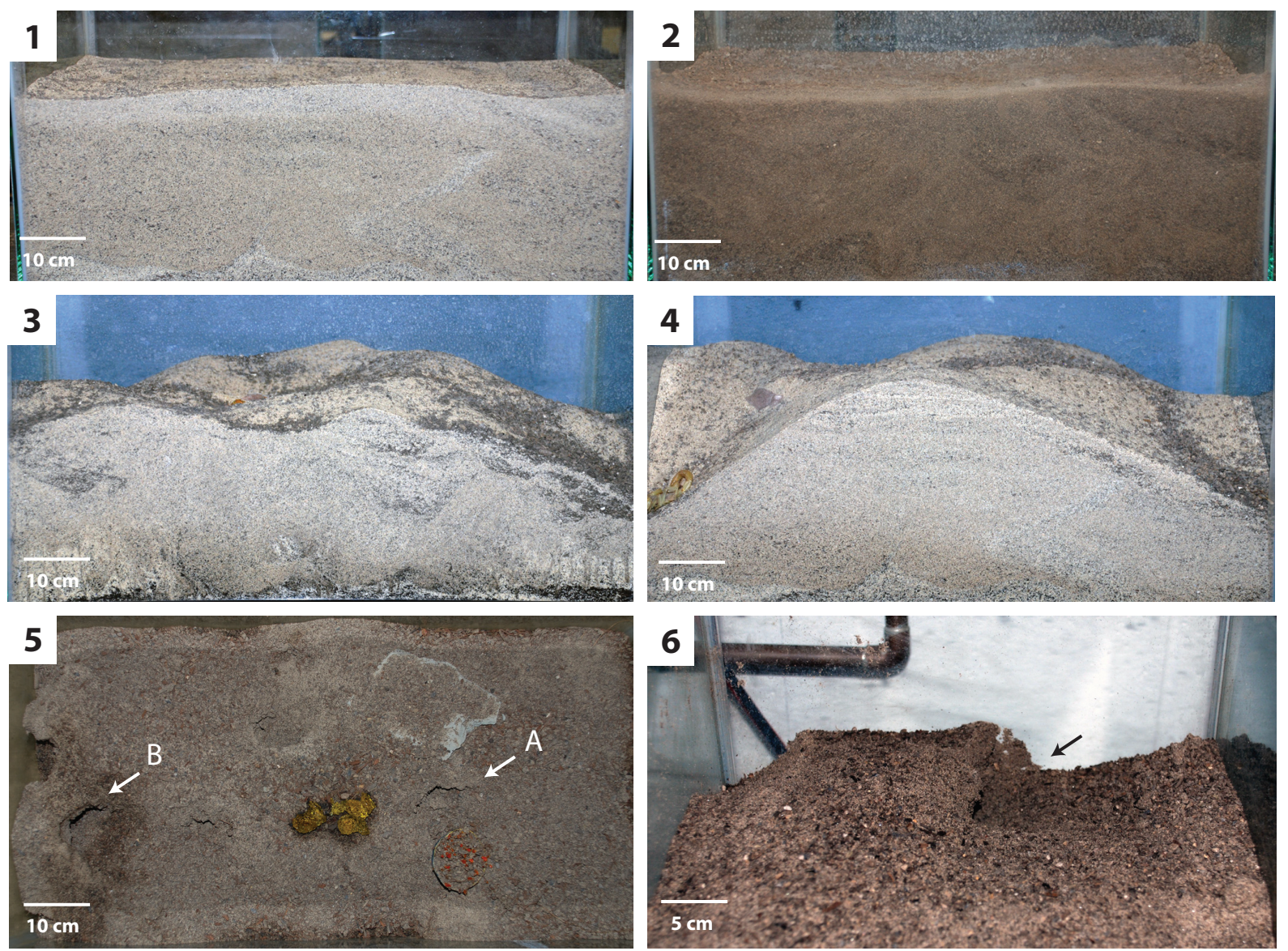

FIGURE 5. Surface morphology produced by $H$. arizonensis burrowing. 1) Experimental tank containing $75 \%$ sand and $25 \%$ clay with a flat, even surface. 2) Experimental tank containing $25 \%$ sand and $75 \%$ clay with a flat, even surface. 3) Ripples and depressions produced in low density sediment after seven days. 4) Ripples and depressions produced in low density sediment after 14 days; surface relief is approximately $15 \mathrm{~cm} .5$ ) Overhead views of a burrow opening beneath a rock (A) and within an excavated pit (B). 6) Oblique view of a burrow opening within an excavated pit.

and would capture and consume the crickets without needing to move.

\section{Surface Morphology}

Specimens of $H$. arizonensis were placed into sediment-filled enclosures with a smooth, horizontal surface (Figure 5.1-2). Over the course of the experimental period, the scorpions produced an undulating surface topography consisting of migrating ripples and depressions (Figure 5.3-4). These structures were most pronounced in the experimental sediment with a low density and no moisture content where the scorpions produced up to $25 \mathrm{~cm}$ of relief. The ripples and mounds were the direct product of the burrowing method of $\mathrm{H}$. arizonensis. The depressions were excavated into the sediment while the ripples were produced as sediment grains were kicked and dragged behind the expanding pit. These features were produced repeatedly in sediment with low density while the scorpion excavated multiple temporary dwellings.

Open burrow constructed by $H$. arizonensis had distinct surface openings (Figure 5.5-6). The openings were ovoid in shape as is typical of scorpions and were typically three times as wide as they were high (Table 2). The burrow openings were on average $3 \mathrm{~cm}$ wide and $1 \mathrm{~cm}$ high at the center of the opening. When the burrow openings were positioned beneath a stone, water dish, or other flat object, the opening was concealed from above (Figure 5.5). If such objects were not used, then a shallow depression was first excavated and the burrow opening was positioned in one of the sides of the pit (Figure 5.5-6). 

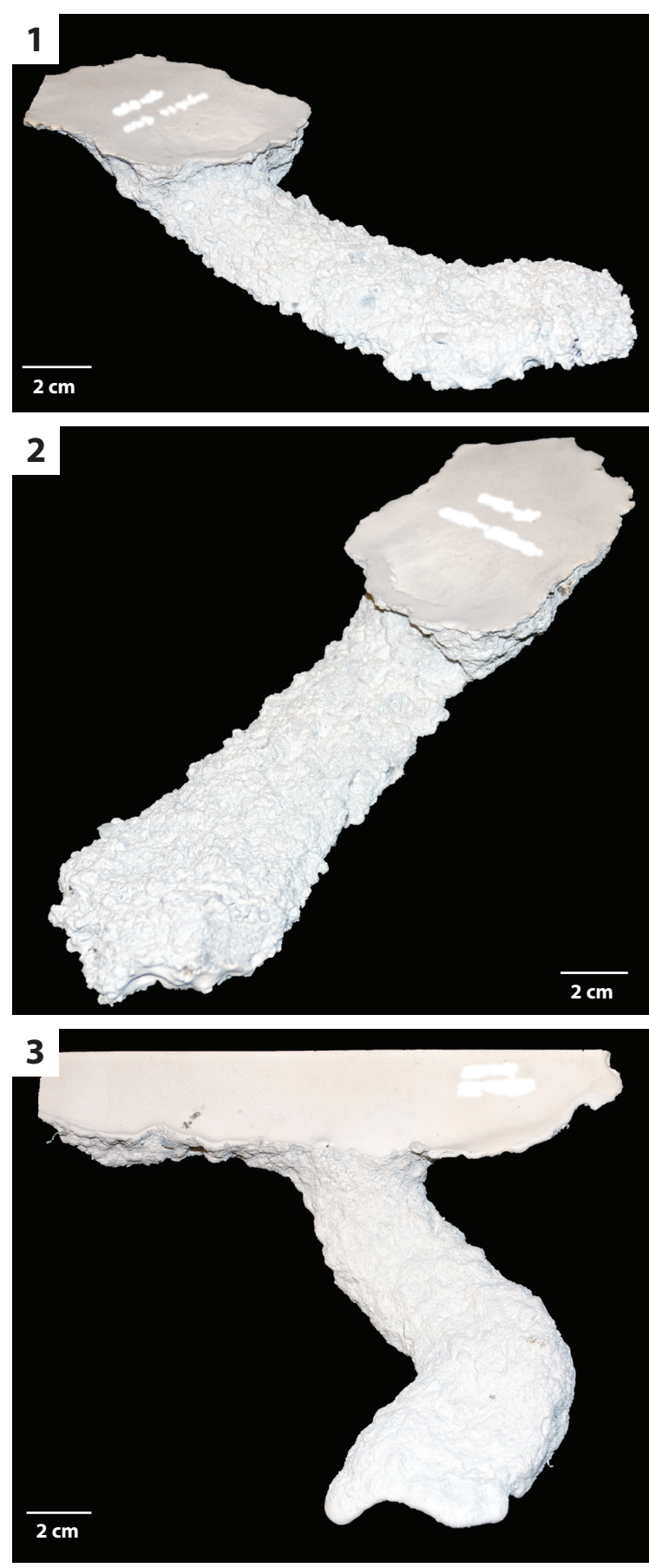

FIGURE 6. Subvertical ramps. 1) Left oblique view of a typical subvertical ramp (DHS2). 2) Right oblique view of a typical subvertical ramp (DHS17). 3) Overhead view of a subvertical ramp with a sharp curve (DHS10).

\section{Burrow Morphology}

Burrows constructed by $\mathrm{H}$. arizonensis were kept open to the surface throughout the experiments. Approximately $90 \%$ of the burrows had a single surface opening. Rarely, more complex bur- rows were constructed with multiple surface openings that led to several interconnected tunnels. There were morphological similarities between all of the burrows produced by the specimens of $H$. arizonensis. The burrows all consisted of sloping ramps leading to laterally expanded chambers. The tunnels and chambers were elliptical in cross section with a width to height ratio of approximately $2-3$. The average width varied only from 3.1-4.9 $\mathrm{cm}$ and the average height from $1.0-2.4 \mathrm{~cm}$. Despite these basic similarities, however, the specimens of $H$. arizonensis produced burrows with a highly variable architectural morphology. Each individual scorpion produced burrows with different architectural morphologies. There were four basic types of burrows including subvertical ramps, Ushaped burrows, helical shafts, and interconnected networks or mazeworks. Each of these four basic burrow morphologies tended to be produced in sediments with specific composition, density, and moisture content (Table 1). The size of the tanks in which the scorpions were housed had no control over the burrow morphologies produced (Table 1).

Subvertical ramps. This burrow architecture includes shallow sloping ramps and tunnels with a variable inclination (Figures 6,7 ). In general a single elliptical surface opening leads to a single narrow and flat tunnel that ends in a vertically expanded chamber. Shafts and tunnels were elliptical in cross section, $35-50 \mathrm{~mm}$ in diameter and 15-30 mm high, and extended for 40-250 mm (Table 2). The tunnels were angled downward into the subsurface from $5-30^{\circ}$ and curved to the left, right, or both as they descended (Figures 67 ). The tunnels extend $30-80 \mathrm{~mm}$ below the sediment surface. Terminal chambers were $5-15 \mathrm{~mm}$ wider and 0-5 $\mathrm{mm}$ higher than the adjacent tunnel. In one specimen, an expanded chamber was produced near the burrow entrance, $140 \mathrm{~mm}$ from the end of the burrow (Figure 7.2-3). This specimen also possessed an extra tunnel branch extending in the opposite direction of the primary tunnel. The majority of the subvertical ramps had a complexity value of 3 which included a single surface opening, single tunnel, and a single chamber (Table 2). The tortuosity of the subvertical ramps varied from 1.0-1.3 (Table 2). Subvertical ramps were produced in all sediment types but were most often produced in sediments with low clay content and substrate density.

U-shaped burrows. This burrow architecture includes two paired elliptical surface openings leading to shafts of variable inclination that join with a laterally expanded connecting tunnel below the 
surface (Figure 8). Shafts and tunnels were elliptical in cross section, 35-50 $\mathrm{mm}$ in diameter and 15-30 mm high, and extended for 10-280 mm from opening to opening (Table 2). The two shafts sloped downward from $20-50^{\circ}$ with one shaft typically sloping $20^{\circ}$ less than the other (Figure 8, Table 2). The base of the U-shaped burrows was 40-80 $\mathrm{mm}$ below the sediment surface. Where the tunnels at the base of the U-shaped burrows were expanded, they were 3-5 mm wider and 0-2 $\mathrm{mm}$ higher. The majority of the U-shaped burrows had a complexity value of 4 which included two surface openings, a single tunnel, and a single chamber (Table 2). The tortuosity of the U-shaped burrows varied from 1.1-1.5 (Table 2). U-shaped burrows were produced in sediment with moderate clay content and substrate density. U-shaped burrows occurred singly or as part of larger interconnected complexes as described below.

Helical burrow. This burrow architecture consists of a single elliptical surface opening leading to a helical shaft that ends in a laterally expanded chamber (Figure 9). Shafts and tunnels comprising the helical burrow were $30-50 \mathrm{~mm}$ in diameter, 10$30 \mathrm{~mm}$ high, and extended for $13-760 \mathrm{~mm}$ reaching a depth of $50-70 \mathrm{~mm}$ (Table 2). The tunnels were angled downward into the subsurface from 5$40^{\circ}$. The inclination of the different elements of the helical burrow varied along its length by as much as $35^{\circ}$. Terminal chambers were $20-30 \mathrm{~mm}$ wider and $0-10 \mathrm{~mm}$ higher than the adjacent tunnel. The majority of the helical burrows had a complexity value of 3 which included a single surface opening, single tunnel, and a single chamber (Table 2). The tortuosity of the helical burrows varied from 3.3-9.0 (Table 2). Helical burrows were produced in sediment with high clay content and substrate density.

Mazeworks. This burrow architecture included multiple interconnected burrows of the other three architectures including subvertical ramps and Ushaped burrows (Figures 10,11). Three examples of mazeworks were successfully cast from the experiments. These mazeworks consist of a subvertical ramp and a U-shaped burrow, two Ushaped burrows and a subvertical ramp, and three $\mathrm{U}$-shaped burrows. The dimensions of the individual elements are the same as isoloated examples of the burrow architecture (Table 2). The mazeworks had complexity values from 7-9 and tortuosities from 1.1-1.3 (Table 2). Mazeworks were produced in soils with high clay content and substrate density.
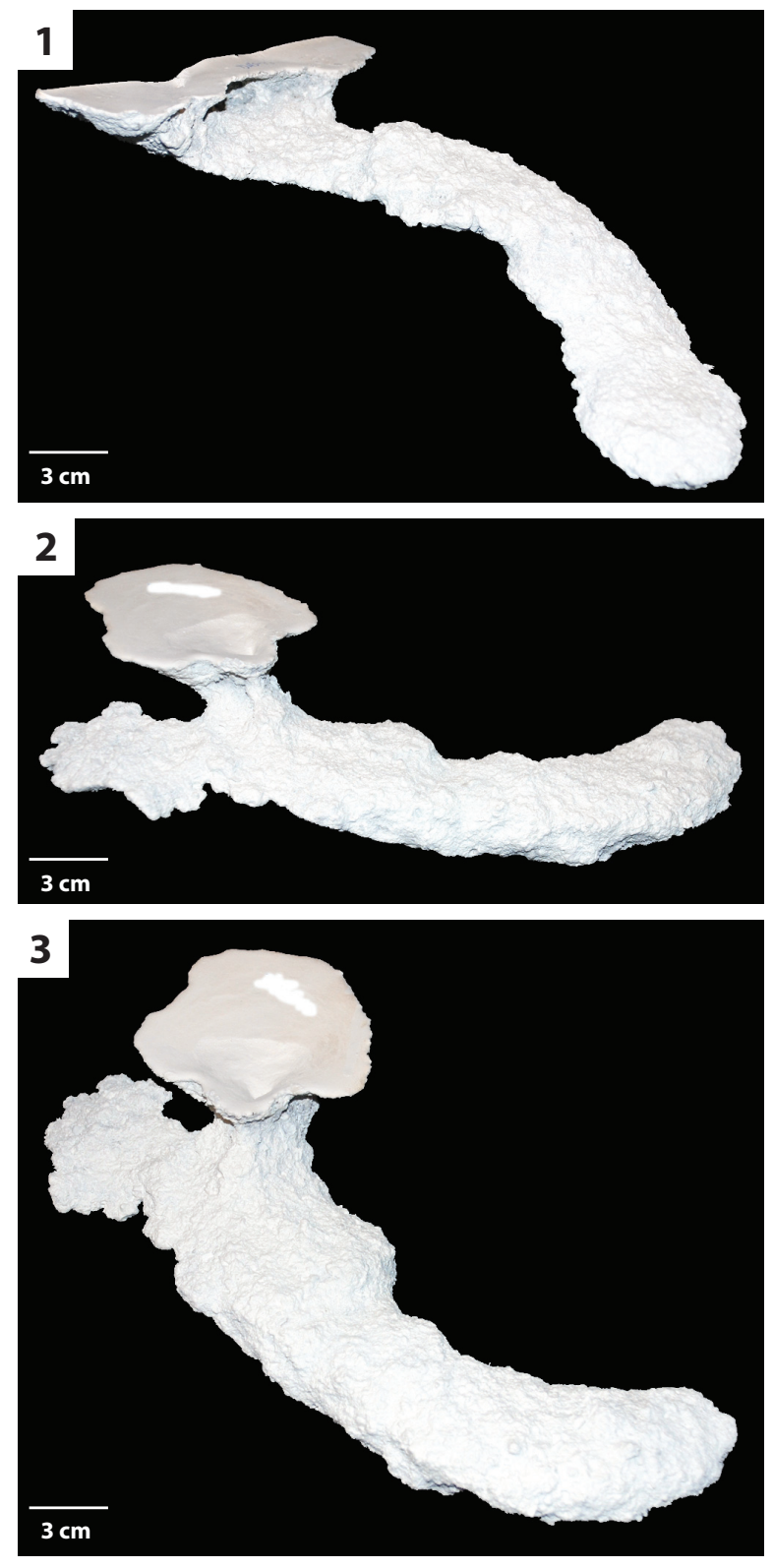

FIGURE 7. Subvertical ramps. 1) Left oblique view of an elongate, curved subvertical ramp (DHS17). 2) Side view of a subvertical ramp with a short branch (DHS16). 3) Overhead view of a subvertical ramp with a short branch and a chamber near the burrow entrance (DHS16).

\section{Biogenic Cross Lamination}

Specimens placed in tanks with sediment characterized by low clay content, low density, and no moisture produced extensive ripple cross lamination (Figure 12). This was a product of the scorpion's burrowing method. In this sediment, the specimens of $\mathrm{H}$. arizonensis were unable to produce permanent open burrows but instead pro- 

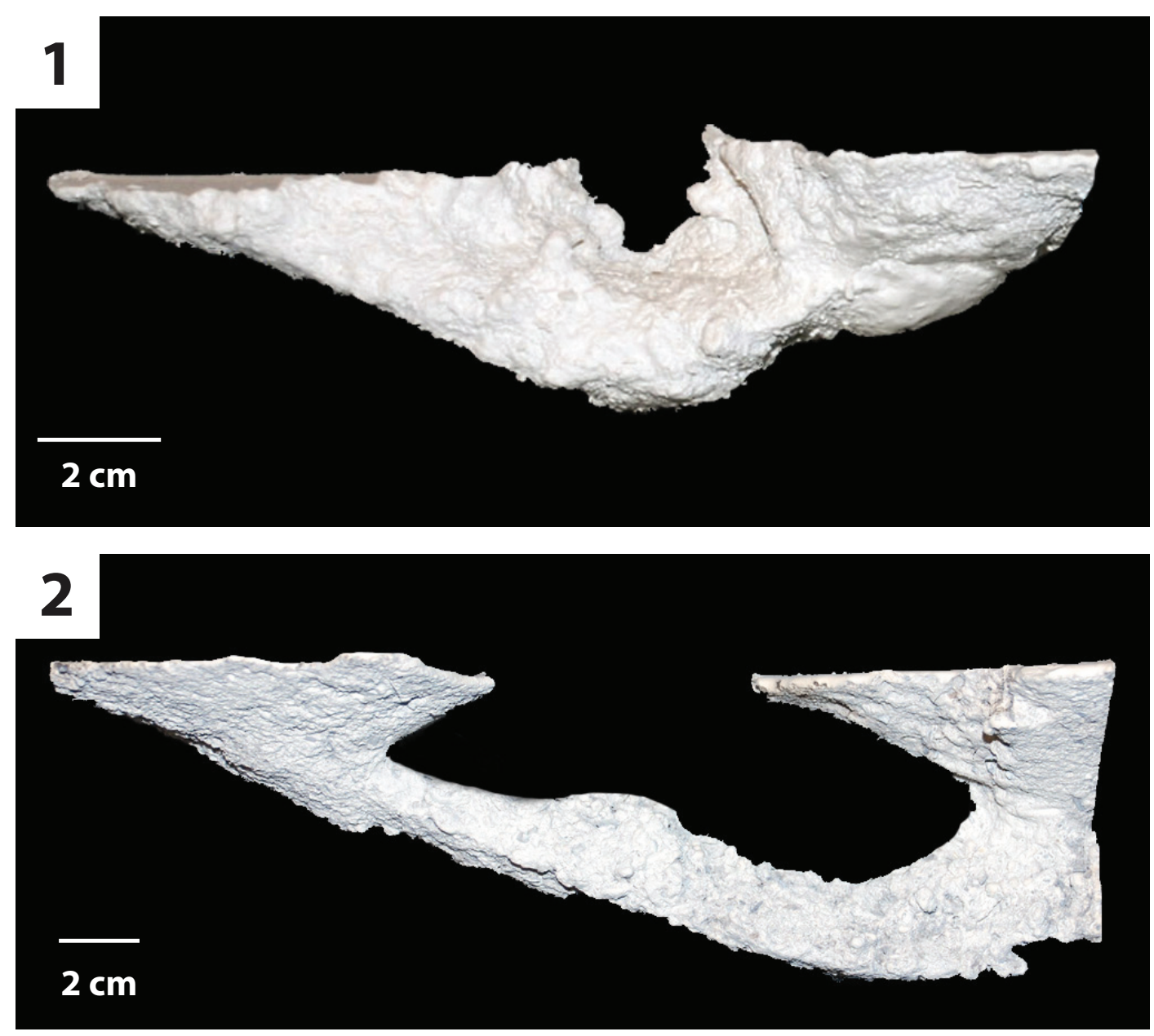

FIGURE 8. U-shaped burrows. 1) Side view of a typical U-shaped burrow (DHS4). 2) Side view of a U-shaped burrow (DHS9) showing the large difference in angles between each shaft $\left(40^{\circ}\right.$ and $\left.90^{\circ}\right)$ typical of $H$. arizonensis burrows of this type.

duced multiple shallow to deep pits and adjacent mounds of sediment. When produced against the wall of the experimental enclosures, the mounds were seen to be composed of sets of laminae inclined $20-25^{\circ}$ from the horizontal. The laminae were produced when the scorpions kicked and dragged sediment particles out of the pits and up against the side of the mounds using their walking legs (Figure 4). The visibility of the laminae was increased through the presence of both clay and sand-sized particles. Through their burrowing process, the scorpions produced cross lamination in the upper $5-8 \mathrm{~cm}$ of the sediment which was originally massive. Individual cross-laminated ripples were $2-5 \mathrm{~cm}$ thick, but some were truncated and overlain by younger ripples (Figure 4). The crosslaminated ripples and associated pits were present throughout the upper surface of the experimental enclosures (Figures 5, 12).

\section{Analysis of Burrow Morphology}

The burrow casts were analyzed using two nonparametric statistical analyses, Bray Curtis Similarity measure and Spearman's rank correlation. The Bray Curtis measure was used to compare the different burrow architectures of $H$. arizonensis in order to find consistent morphological traits, those features which may be diagnostic of burrows produced by $\mathrm{H}$. arizonensis (Table 3 ). The burrows of $H$. arizonensis were also compared with burrow casts of two other burrowing arachnids, $P$. imperator and M. giganteus (Figure 13), to determine if they could be shown to be significantly different using the 10 different quantitative measurements employed in this study. One diagnostic 

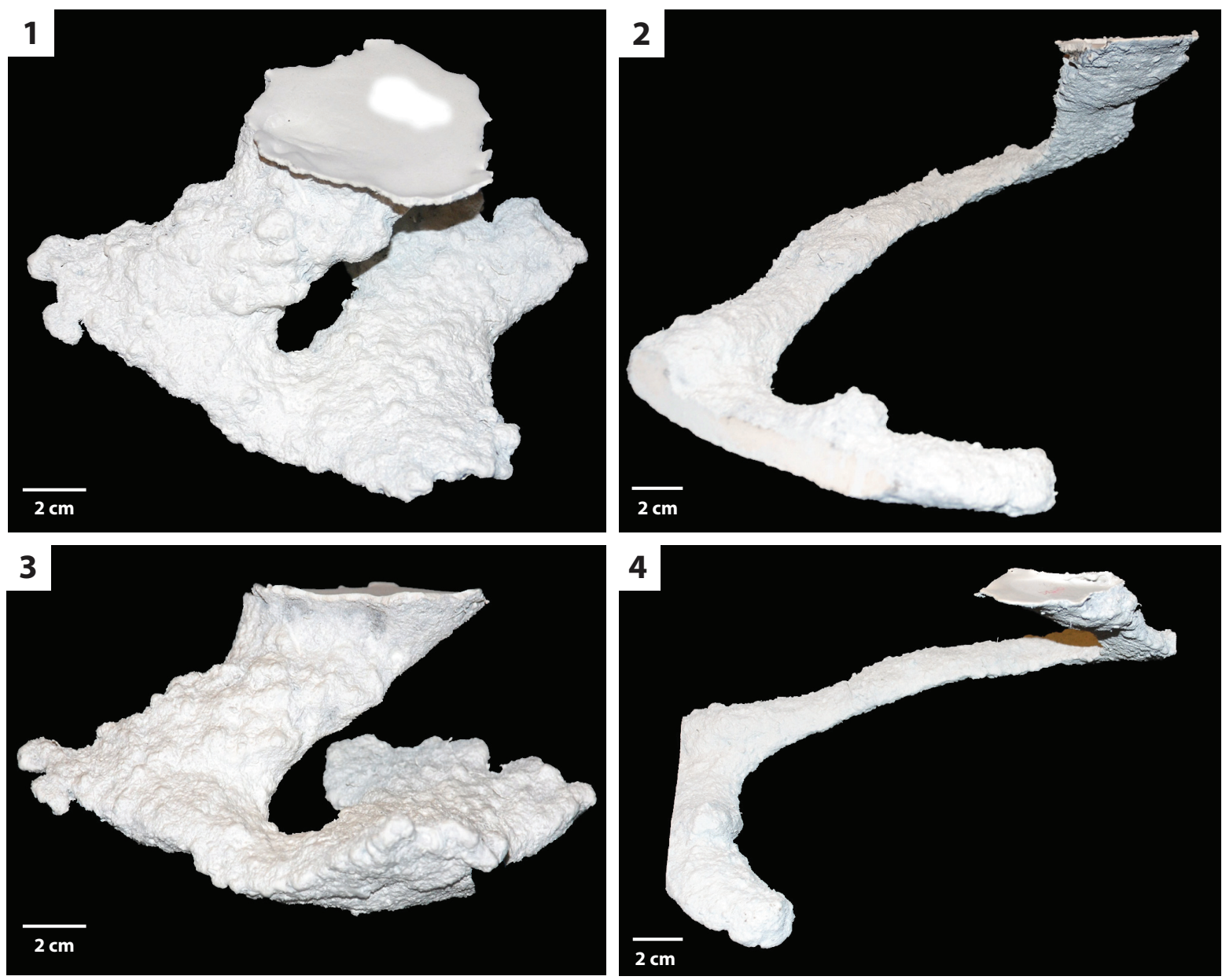

FIGURE 9. Helical burrow casts. 1) Oblique view of a short, highly tortuous helical burrow (DHS3). The terminal chamber is directly below the burrow opening. 2) Side view of an elongate $(76 \mathrm{~cm})$ helical burrow with a low tortuosity (DHS15). 3) Side view of a highly tortuous helical burrow (DHS3). 4) Oblique view of an elongate helical burrow with a low tortuosity (DHS15)

burrow cast for each of these two species was selected from those produced in the laboratory. Spearman's rank correlation was used to compare different quantitative morphological properties of the $H$. arizonensis burrows sediment density to determine if there was a significant correlation (Table 4).

Burrows of $\boldsymbol{H}$. arizonensis. In general, the burrows of $H$. arizonensis were found to be highly to moderately similar based upon the 10 quantitative properties tested with similarity indices mostly ranging from 0.9-0.7 (Table 3). This was especially true when comparing burrows with the same architectural morphology such as subvertical ramps (Table 3.2) and mazeworks (Table 3.3). There were specific burrows that had low similarity indices (0.5-0.4), but these typically occurred when comparing burrows across different architectures, par- ticularly comparisons between subvertical ramps and mazeworks (DHS4, DHS5). These two architectures had significant differences in the 10 quantitative properties including the number of surface openings, length, complexity, and tortuosity. Additional low similarity indices were found when comparing the large helical burrow (DHS15) to shallow ramps with low total lengths and shallow depths. Combined with the difference in tortuosity due to their basic architectural difference, they were found to be dissimilar. The large helical burrow was also found to be dissimilar to the small, shallow helical burrow (DHS7) for the same reason (Table 3.4).

Comparison with Other Arachnid Burrows. When compared to a burrow cast of $P$. imperator and $M$. giganteus, the burrows of $H$. arizonensis were found to be relatively similar to those of the emperor scorpion (average similarity index 0.7 ) 

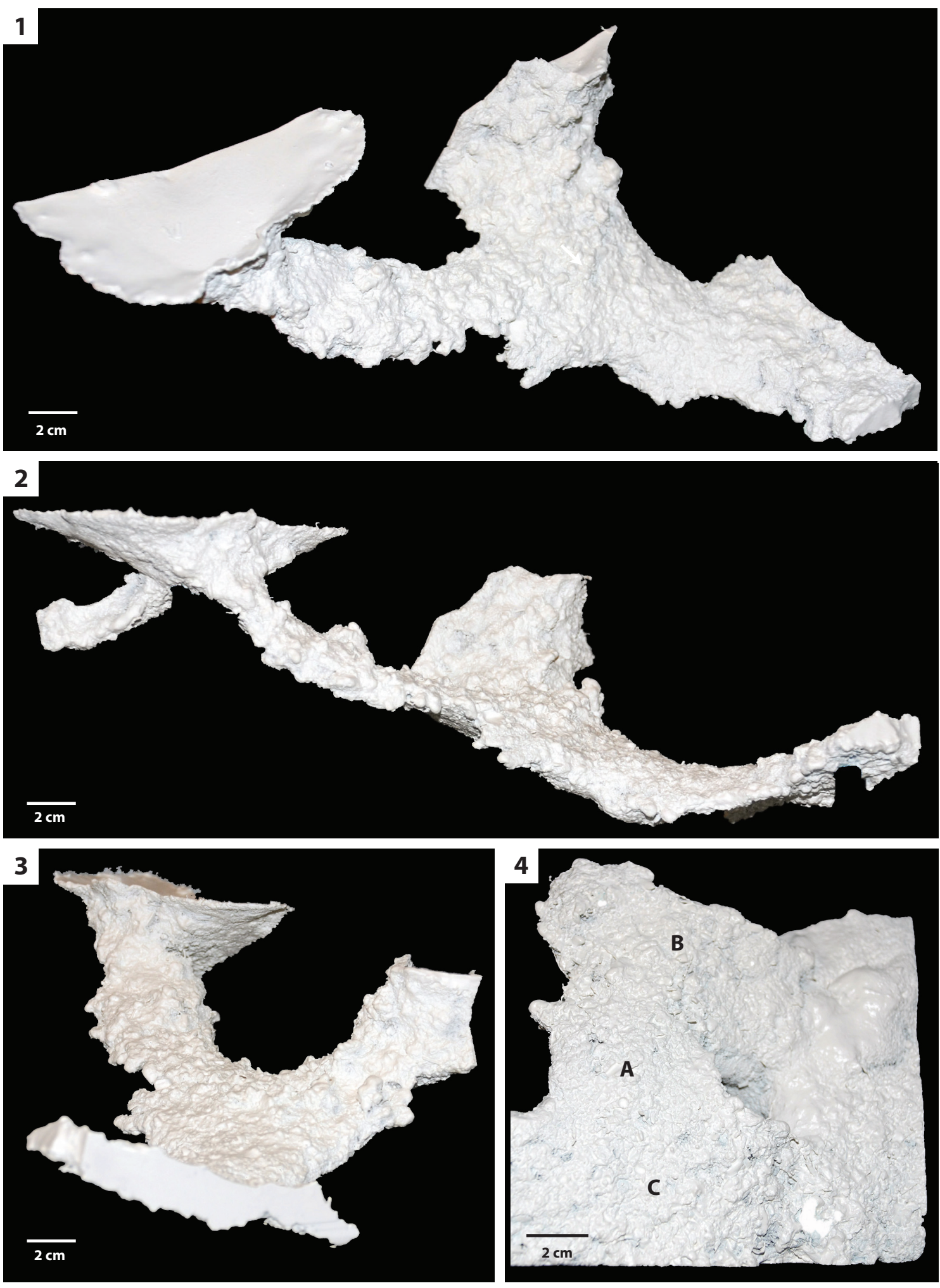

FIGURE 10. Mazeworks. 1) Overhead view of a mazework consisting of a U-shaped burrow and two subvertical ramps (DHS8). 2, 3) Side views of mazework consisting of a U-shaped burrow and two subvertical ramps (DHS8). 4) Underside of a mazework (DHS4); a short tunnel (A) connects a subvertical ramp (B) and a U-shaped burrow (C). 

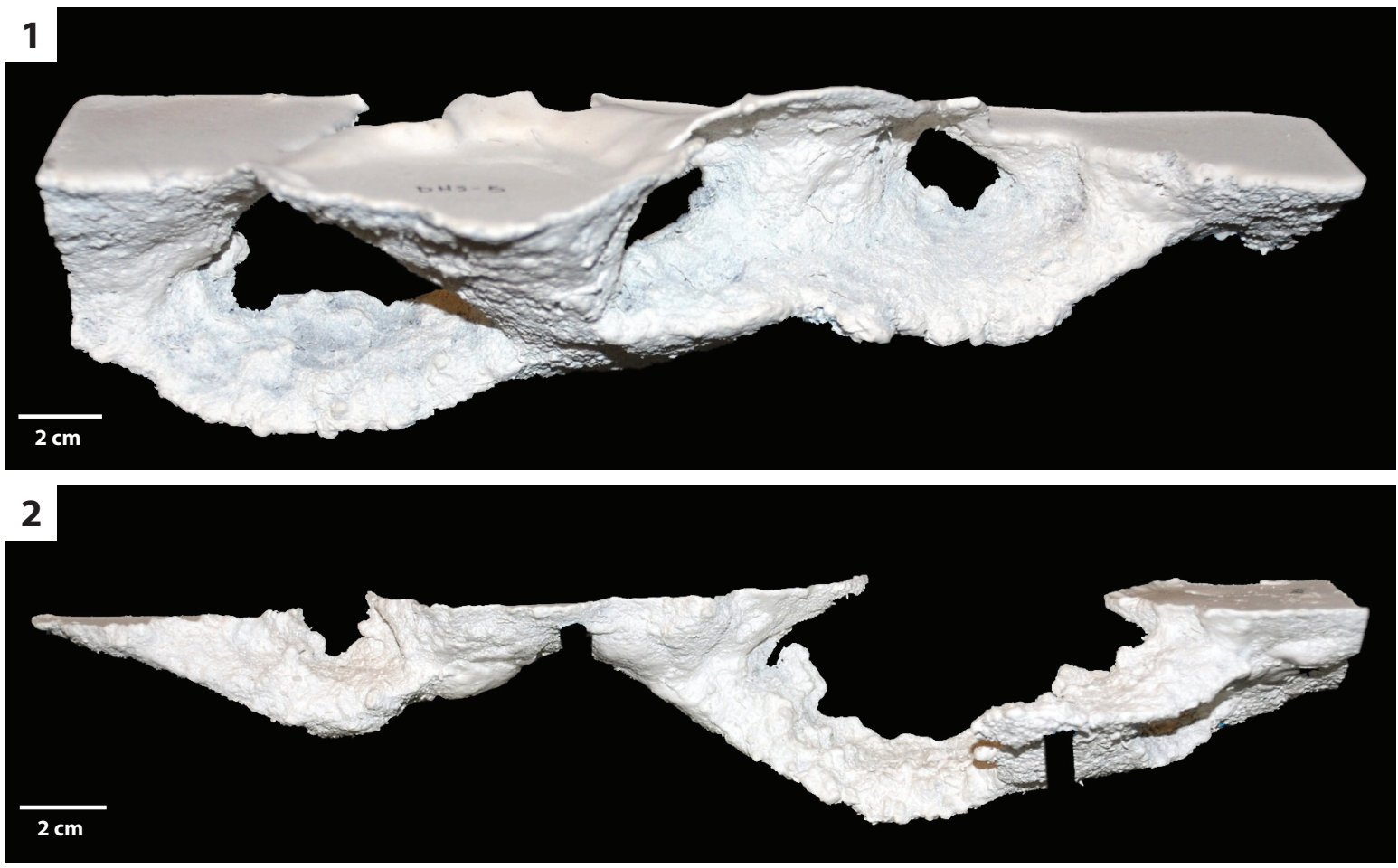

FIGURE 11. Mazeworks. 1) Side view of a mazework consisting of three U-shaped burrows (DHS5). 2) Side view of a mazework consisting of two U-shaped burrows and a subvertical ramp (DHS4).

and different from that of the whip scorpion (average similarity index 0.5) (Table 3.1). The burrow cast of $P$. imperator did have similar quantitative properties to those of $H$. arizonensis including the same average number of surface openings, $\mathrm{W}: \mathrm{H}$ ratio, average slope, complexity, and tortuosity as most of the desert scorpion burrows (Table 2). The major difference between the burrows of $H$. arizonensis and $P$. imperator were the average width, height, and circumference each of which was significantly larger in the emperor scorpion burrow. The burrow of $M$. giganteus was found to be dissimilar to most of the $H$. arizonensis burrows with the exception of those with a mazework architecture. While the average width, height, circumference, and width:height ratio were similar, the number of surface openings, total length, average slope, and complexity were significantly greater in the M. giganteus burrow than the typical $H$. arizonensis burrow (Table 2). While the burrow morphology of these two species may also vary, the casts used in this analysis were the most commonly produced and are therefore considered to be diagnostic of the species.
Environmental Controls on Burrow Morphology. Sediment density was observed to have the greatest control on burrow morphology during the experiments (Table 1). There was no observed change in burrow architecture or form with changes in sediment moisture (with the exception of excluding the production of open burrows) or space availability. Spearman's rank correlation was used to determine if there was a statistically significant correlation between any quantitative aspect of burrow morphology and average sediment density defined as low, moderate, and high in this study (Table 4). Eight different analyses were run, but only total length was shown to have a significantly positive relationship with sediment density $(R s=0.82)$. Complexity and tortuosity were initially considered to be effective substitutes for architecture, but these did not indicate a significant relationship with sediment density despite the observed pattern. Total length, however, was related to burrow architecture in that mazeworks (DHS4, DHS5, DHS8) had the highest total lengths with exception of a single helical burrow (DHS15) and a subvertical ramp (DHS16) both of which were also produced in sediment with a high density (Table 2). 

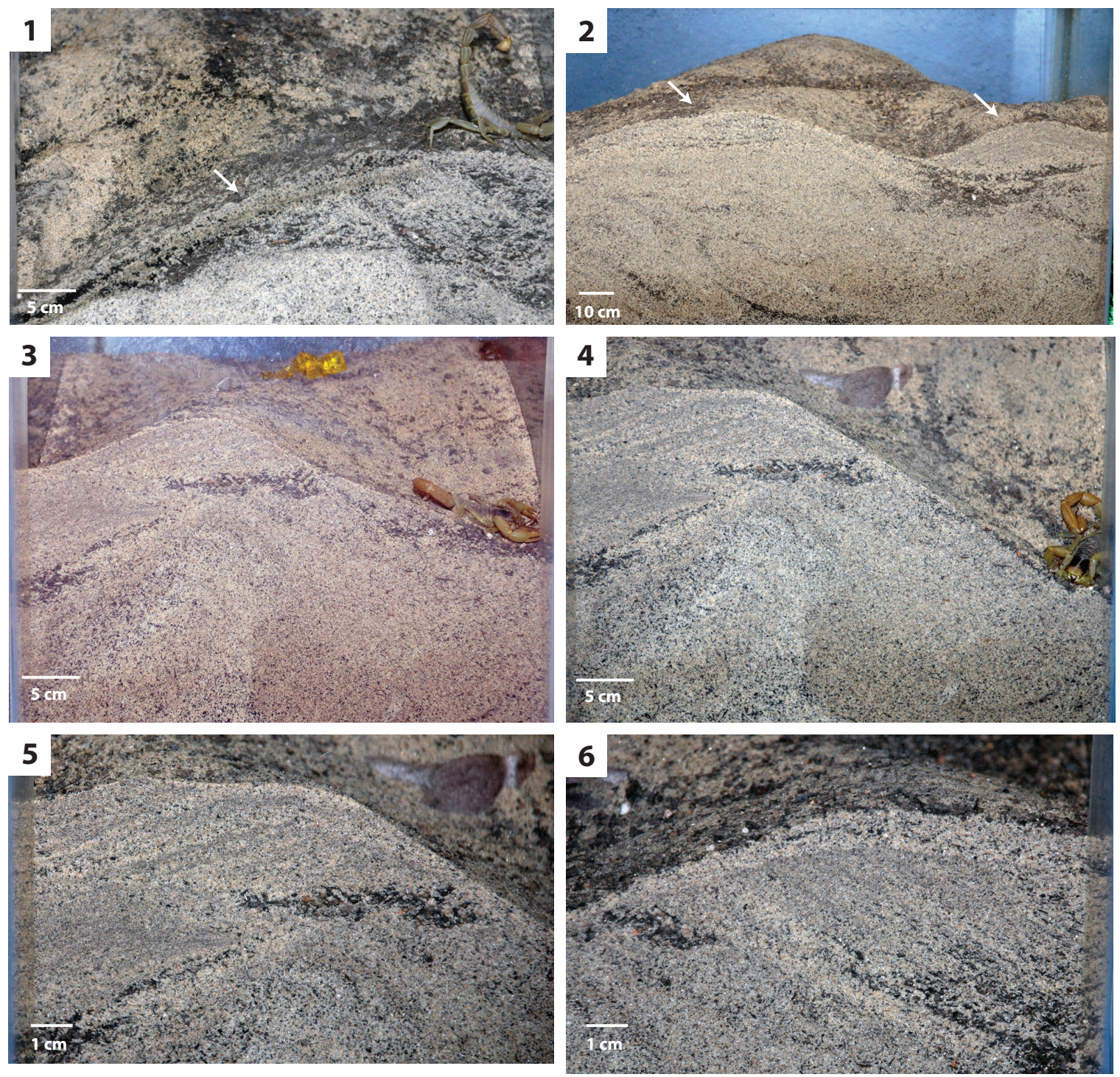

FIGURE 12. Biogenic cross lamination. 1) Production of laminae (at arrow) by a specimen of $H$.arizonensis during excavation by the kick method. 2) Ripple forms produced by $\mathrm{H}$. arizonensis (at arrows) with cross lamination visible in cross section. 3) Two stacked cross-laminated ripple forms. 4, 5) Stacked ripples show in (3) after two days; the upper ripple has grown and migrated to the left. 6) Steeply dipping set of biogenic cross laminae.

\section{DISCUSSION}

\section{Burrow Morphology and Tracemaker}

Even though only one species of scorpion was used in these experiments, four different types of burrow architectures were produced. The different architectural morphologies were produced not only by individual specimens of the same species but also by the same specimens in different experiments. The concept that an individual organism or species is capable of producing multiple burrow morphologies is well-known by ichnologists and important to the interpretation of ichnofossils (Bro- mley, 1996). What is vital to understanding this ichnological principle is that other factors also control burrow morphology besides the tracemaking organism including behavior and the properties of the burrowing medium (sediment, soil, rock) (Bromley, 1996).

Despite the variation in overall architectural form there were similarities among the four different burrow types produced by $H$. arizonensis, which will be useful in the identification of burrows produced by this species of scorpion and scorpions in general. The properties that were found to be similar among the different burrow types of $\mathrm{H}$. ari- 
TABLE 3. Bray Curtis Similarity measure results. 1. Comparison matrix of all burrow casts. 2. Comparison matrix of subvertical ramps. 3. Comparison matrix of mazeworks. 4. Comparison matrix of helical burrows. DHS: Hadrurus arizonensis, ES: Pandinus imperator, WS: Mastigoproctus giganteus, SR: subvertical ramp, UB: U-shaped burrow, HB: helical burrow, MW: mazework.

1

\begin{tabular}{|c|c|c|c|c|c|c|c|c|c|}
\hline & $\begin{array}{c}\text { DHS1 } \\
\text { (SR) }\end{array}$ & $\begin{array}{c}\text { DHS2 } \\
\text { (SR) }\end{array}$ & $\begin{array}{c}\text { DHS3 } \\
\text { (HB) }\end{array}$ & $\begin{array}{l}\text { DHS4 } \\
\text { (MW) }\end{array}$ & $\begin{array}{l}\text { DHS5 } \\
\text { (MW) }\end{array}$ & $\begin{array}{l}\text { DHS6 } \\
\text { (SR) }\end{array}$ & $\begin{array}{c}\text { DHS7 } \\
\text { (HB) }\end{array}$ & $\begin{array}{l}\text { DHS8 } \\
\text { (MW) }\end{array}$ & $\begin{array}{l}\text { DHS9 } \\
\text { (UB) }\end{array}$ \\
\hline DHS1 (SR) & & 0.8 & 0.7 & 0.6 & 0.6 & 0.9 & 0.9 & 0.7 & 0.7 \\
\hline DHS2 (SR) & 0.8 & & 0.7 & 0.5 & 0.5 & 0.8 & 0.7 & 0.6 & 0.5 \\
\hline DHS3 (HB) & 0.7 & 0.7 & & 0.7 & 0.7 & 0.7 & 0.8 & 0.8 & 0.8 \\
\hline DHS4 (MW) & 0.6 & 0.5 & 0.7 & & 0.9 & 0.5 & 0.6 & 0.8 & 0.8 \\
\hline DHS5 (MW) & 0.6 & 0.5 & 0.7 & 0.9 & & 0.6 & 0.6 & 0.9 & 0.9 \\
\hline DHS6 (SR) & 0.9 & 0.8 & 0.7 & 0.5 & 0.6 & & 0.9 & 0.6 & 0.6 \\
\hline DHS7 (HB) & 0.9 & 0.7 & 0.8 & 0.6 & 0.6 & 0.9 & & 0.7 & 0.7 \\
\hline DHS8 (MW) & 0.7 & 0.6 & 0.8 & 0.8 & 0.9 & 0.6 & 0.7 & & 0.9 \\
\hline DHS9 (UB) & 0.7 & 0.5 & 0.8 & 0.8 & 0.9 & 0.6 & 0.7 & 0.9 & \\
\hline DHS10 (SR) & 0.8 & 0.9 & 0.7 & 0.5 & 0.6 & 0.8 & 0.8 & 0.7 & 0.6 \\
\hline DHS11 (SR) & 1.0 & 0.8 & 0.7 & 0.6 & 0.6 & 0.9 & 0.9 & 0.7 & 0.7 \\
\hline DHS12 (SR) & 0.8 & 0.9 & 0.8 & 0.6 & 0.6 & 0.7 & 0.7 & 0.7 & 0.6 \\
\hline DHS13 (SR) & 0.8 & 0.8 & 0.8 & 0.6 & 0.6 & 0.8 & 0.8 & 0.7 & 0.7 \\
\hline DHS14 (SR) & 0.8 & 0.8 & 0.8 & 0.7 & 0.7 & 0.8 & 0.8 & 0.8 & 0.7 \\
\hline DHS15 (HB) & 0.5 & 0.5 & 0.7 & 0.8 & 0.7 & 0.5 & 0.5 & 0.7 & 0.6 \\
\hline DHS16 (SR) & 0.7 & 0.7 & 0.8 & 0.8 & 0.8 & 0.7 & 0.7 & 0.8 & 0.7 \\
\hline DHS17 (SR) & 0.7 & 0.8 & 0.9 & 0.7 & 0.7 & 0.7 & 0.7 & 0.8 & 0.7 \\
\hline ES1 (HB) & 0.7 & 0.6 & 0.8 & 0.7 & 0.7 & 0.6 & 0.7 & 0.8 & 0.7 \\
\hline WS1 (MW) & 0.5 & 0.4 & 0.6 & 0.9 & 0.9 & 0.5 & 0.5 & 0.8 & 0.8 \\
\hline
\end{tabular}

zonensis included the average width, average height, width:height ratio, and the average circumference. These properties of the burrows appear to be related to the morphology of the scorpions themselves since they closely resemble the dimensions of the animal, particularly in the tunnels and shaft. The greatest variation in internal burrow dimensions occurred within the chambers, which appeared to vary in maximum size due to the total time of occupation, sediment density, and differences in individual behavior.

Comparison with burrows produced by other arachnids, including another species of burrowing scorpion, also indicates diagnostic characteristics of $H$. arizonensis burrows. Burrows of $H$. arizonensis tended to have smaller internal dimensions (width, height, circumference) than those of $P$. imperator. Individuals of $P$. imperator do tend to be somewhat larger than those of $H$. arizonensis, but they also tend to live in groups of two to five individuals within a single burrow (Polis, 1990). This behavioral difference accounts for the quantitative difference in burrow morphology. The burrow of $M$. giganteus was more complex than the typical burrow of $H$. arizonensis, with more surface openings, greater total length, and a higher complexity value resulting from a mazework architecture. Despite the general difference in dimensions, the relationship between these dimensions particularly the width:height ratio are similar among the three arachnid burrows examined here. This similarity in cross-sectional shape may be useful in identifying tracemakers with body morphologies similar to these animals.

\section{Burrow Morphology and Behavior}

All of the open burrows produced by specimens of $H$. arizonensis, despite their differences in architectural morphology, were used for the same behavioral purposes, dwelling and feeding. The common properties of the different burrow morphologies were related to these two basic behaviors. In addition, the burrowing method of kicking and dragging sediment along the base of the bur- 
TABLE 3 (continued).

1

\begin{tabular}{|c|c|c|c|c|c|c|c|c|c|c|}
\hline & $\begin{array}{c}\text { DHS10 } \\
\text { (SR) }\end{array}$ & $\begin{array}{c}\text { DHS11 } \\
\text { (SR) }\end{array}$ & $\begin{array}{c}\text { DHS12 } \\
\text { (SR) }\end{array}$ & $\begin{array}{c}\text { DHS13 } \\
\text { (SR) }\end{array}$ & $\begin{array}{c}\text { DHS14 } \\
\text { (SR) }\end{array}$ & $\begin{array}{c}\text { DHS15 } \\
\text { (HB) }\end{array}$ & $\begin{array}{c}\text { DHS16 } \\
\text { (SR) }\end{array}$ & $\begin{array}{c}\text { DHS17 } \\
\text { (SR) }\end{array}$ & $\begin{array}{l}\text { ES1 } \\
\text { (HB) }\end{array}$ & $\begin{array}{l}\text { WS1 } \\
\text { (MW) }\end{array}$ \\
\hline DHS1 (SR) & 0.8 & 1.0 & 0.8 & 0.8 & 0.8 & 0.5 & 0.7 & 0.7 & 0.7 & 0.5 \\
\hline DHS2 (SR) & 0.9 & 0.8 & 0.9 & 0.8 & 0.8 & 0.5 & 0.7 & 0.8 & 0.6 & 0.4 \\
\hline DHS3 (HB) & 0.7 & 0.7 & 0.8 & 0.8 & 0.8 & 0.7 & 0.8 & 0.9 & 0.8 & 0.6 \\
\hline DHS4 (MW) & 0.5 & 0.6 & 0.6 & 0.6 & 0.7 & 0.8 & 0.8 & 0.7 & 0.7 & 0.9 \\
\hline DHS5 (MW) & 0.6 & 0.6 & 0.6 & 0.6 & 0.7 & 0.7 & 0.8 & 0.7 & 0.7 & 0.9 \\
\hline DHS6 (SR) & 0.8 & 0.9 & 0.7 & 0.8 & 0.8 & 0.5 & 0.7 & 0.7 & 0.6 & 0.5 \\
\hline DHS7 (HB) & 0.8 & 0.9 & 0.7 & 0.8 & 0.8 & 0.5 & 0.7 & 0.7 & 0.7 & 0.5 \\
\hline DHS8 (MW) & 0.7 & 0.7 & 0.7 & 0.7 & 0.8 & 0.7 & 0.8 & 0.8 & 0.8 & 0.8 \\
\hline DHS9 (UB) & 0.6 & 0.7 & 0.6 & 0.7 & 0.7 & 0.6 & 0.7 & 0.7 & 0.7 & 0.8 \\
\hline DHS10 (SR) & & 0.8 & 0.9 & 0.9 & 0.9 & 0.5 & 0.8 & 0.8 & 0.6 & 0.5 \\
\hline DHS11 (SR) & 0.8 & & 0.7 & 0.8 & 0.8 & 0.5 & 0.7 & 0.7 & 0.7 & 0.5 \\
\hline DHS12 (SR) & 0.9 & 0.7 & & 0.9 & 0.9 & 0.6 & 0.8 & 0.9 & 0.7 & 0.5 \\
\hline DHS13 (SR) & 0.9 & 0.8 & 0.9 & & 0.9 & 0.6 & 0.8 & 0.9 & 0.7 & 0.5 \\
\hline DHS14 (SR) & 0.9 & 0.8 & 0.9 & 0.9 & & 0.6 & 0.9 & 0.9 & 0.7 & 0.6 \\
\hline DHS15 (HB) & 0.5 & 0.5 & 0.6 & 0.6 & 0.6 & & 0.7 & 0.6 & 0.7 & 0.8 \\
\hline DHS16 (SR) & 0.8 & 0.7 & 0.8 & 0.8 & 0.9 & 0.7 & & 0.9 & 0.8 & 0.7 \\
\hline DHS17 (SR) & 0.8 & 0.7 & 0.9 & 0.9 & 0.9 & 0.6 & 0.9 & & 0.7 & 0.6 \\
\hline ES1 (HB) & 0.6 & 0.7 & 0.7 & 0.7 & 0.7 & 0.7 & 0.8 & 0.7 & & 0.7 \\
\hline WS1 (MW) & 0.5 & 0.5 & 0.5 & 0.5 & 0.6 & 0.8 & 0.7 & 0.6 & 0.7 & \\
\hline
\end{tabular}

row using the walking legs resulted in some common architectural and surficial morphologies.

The simplest burrow architecture produced by $H$. arizonensis was the subvertical ramp. These burrows were of variable length $(40-250 \mathrm{~mm}$ ) but ended with an expanded chamber. These simple burrows provided the basic requirement of a subsurface shelter for the scorpion. In nature, these burrows provide protection from extreme environmental conditions and predators (Polis, 1990). Burrows with this morphology were produced quickly, often in less than 12 hours, while the chamber was expanded over longer time periods. The rapid production of these burrows highlights the importance of burrows to this group of scorpions. During the experiments, specimens of $H$. arizonensis were rarely observed on the surface, and this was only during dark intervals. The presence of these scorpions in a particular sedimentary environment, therefore, will result in the production of burrows.

The laterally expanded chamber at the base of most $H$. arizonensis burrows serve as dwelling structures and, perhaps more importantly, allow the scorpion to turn around while below the surface.
The tunnels are generally only as wide as the scorpion and therefore the animal cannot turn around once it has entered the burrow. The laterally expanded chamber provides the scorpion the room to reorient itself inside the burrow. The expanded chamber is typically located at base of burrow but one was present near the surface opening suggesting that the end of the burrow is not necessarily a significant end point for the structure. In fact, several burrows were extended and deepened after their initial construction. The specimens were observed to spend time in the burrow tunnel, often just below the burrow entrance. Much of the time spent in the burrow tunnel appeared to be related to feeding behavior. It was in this position that the scorpions were observed to capture and consume prey animals that entered the burrow. This behavior was not observed when the scorpion was within the chamber.

Over time, some subvertical ramps were expanded into U-shaped burrows. To do this, the scorpion burrowed from the subsurface upward until it broke through to the surface to produce a new opening. The excavated sediment was 
TABLE 3 (continued).

2

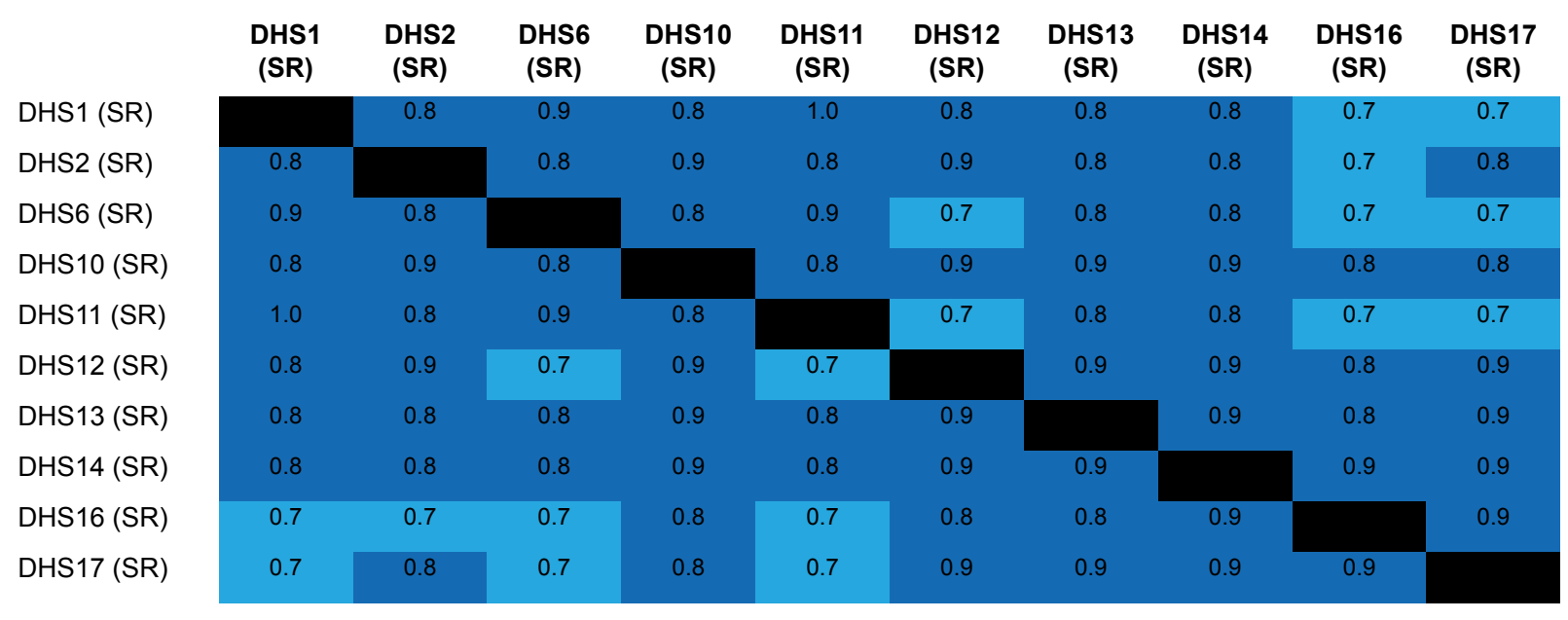

3

\begin{tabular}{lccc} 
& $\begin{array}{c}\text { DHS4 } \\
\text { (MW) }\end{array}$ & $\begin{array}{c}\text { DHS5 } \\
\text { (MW) }\end{array}$ & $\begin{array}{c}\text { DHS8 } \\
\text { (MW) }\end{array}$ \\
\hline DHS4 (MW) & & 0.9 & 0.8 \\
DHS5 (MW) & 0.9 & & 0.9 \\
\hline DHS8 (MW) & 0.8 & 0.9 & \\
\hline
\end{tabular}

4

\begin{tabular}{cccc} 
& $\begin{array}{c}\text { DHS3 } \\
\text { (HB) }\end{array}$ & $\begin{array}{c}\text { DHS7 } \\
\text { (HB) }\end{array}$ & $\begin{array}{c}\text { DHS15 } \\
\text { (HB) }\end{array}$ \\
\hline DHS3 (HB) & & 0.8 & 0.7 \\
DHS7 (HB) & 0.8 & & 0.5 \\
\hline DHS15 (HB) & 0.7 & 0.5 & \\
\hline
\end{tabular}

removed through the older burrow opening. The construction of two surface openings appeared to provide an increase in hunting efficiency. A single surface opening tended to attract one or two prey animals; two surface openings doubled this effect. In some experiments lasting 21 days, even more complex structures were produced by linking together multiple subvertical ramps and U-shaped burrows in the subsurface. These mazeworks included 3-5 surface openings leading to an interconnected series of tunnels and shafts. Each of these surface openings served as a trap for prey animals, and the scorpion was seen just below each of them at different times.

The basic cross-sectional form of the burrow openings, tunnels, shafts, and chambers were at least partially related to the burrowing methods of $H$. arizonensis. First, the tunnels, shafts, and chambers of the $H$. arizonensis burrows possessed relatively flat floors, arching walls and concave roofs (Figures 6, 7, 8, 9, 10, 11). These features were the result of the burrowing mechanism in which sediment was removed primarily from beneath the animal by the walking legs and along the base of the burrow. Little excavation was focused along the sides and top of the burrows. This burrow method also resulted in a surficial morphology characterized by relatively smooth floors and rough sides and ceilings.

\section{Burrow Morphology and Sediment Properties}

Observations during and after the experiments indicated that differences in sediment conditions, specifically sediment density and moisture, influenced the architectural morphology of the burrows produced by $H$. arizonensis and, in an extreme example, whether or not open burrows could be constructed. Space availability was found 

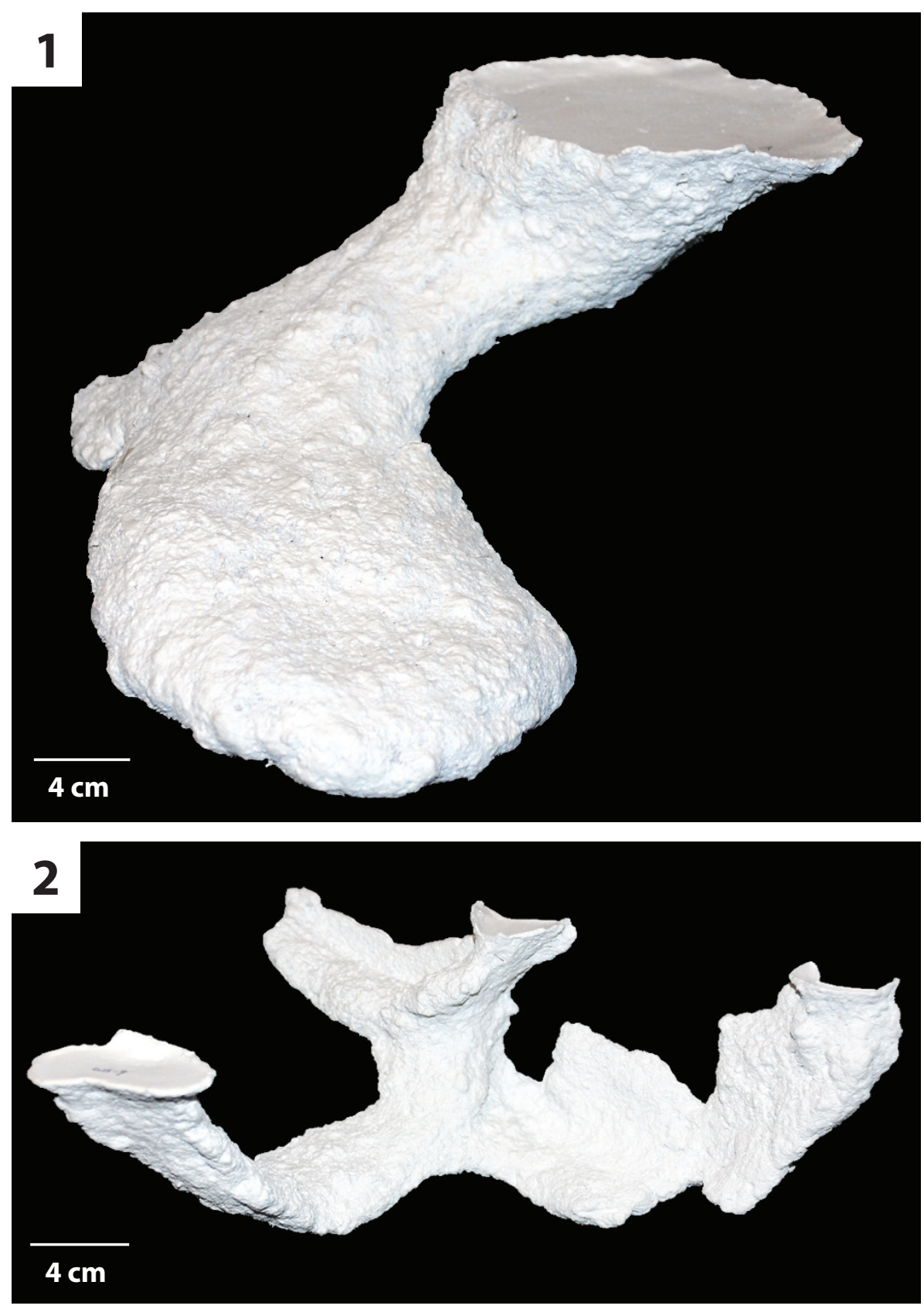

FIGURE 13. Burrows produce by other arachnids. 1) Oblique view of a large helical burrow produced by Pandinus imperator. 2) Oblique view of a mazework produced by Mastigoproctus giganteus.

to have no impact on the burrow architectures that were produced (Table 1 ).

Overall, sediment density, which was directly related to the percent clay content of the sediment, led to more complex burrow architectures such as helical burrows and mazeworks. These burrow architectures were not produced in sediments with low or moderate substrate density (Table 1). Experiments using sediment with lower bulk densities (0.4-1.4) produced only subvertical ramps and U- shaped burrows. These simpler architectures, however, were also produced in high density sediment. The fundamental control on the production of more complex burrow types, therefore, appears to be the composition of the sediment. Greater clay content and sediment density allowed for more complex open burrows to be produced and maintained. Sediment with lower clay content and bulk density tended to collapse before more complex structures could be completed. This is, in part, due 
to the scorpions which do not produce a reinforced lining. Such linings, produced from clay pellets, fecal material, or mucus, are used by other burrowing animals (e.g., spiders, shrimp, crayfish, crabs, polychaetes) to maintain open burrows in less cohesive substrates (Bromley, 1996). Helical burrows are typically interpreted as a means of temperature and moisture regulation (Smith, 1987; Meyer, 1999). There were, however, no changes in these parameters of the experimental design where these types of burrows were produced. Instead only sediment composition and density was altered. Analysis of burrow morphology by Spearman's rank correlation showed that the total length of the burrows did have a positive relationship with sediment density (Table 4.4). Higher burrow lengths were associated with more complex burrow architectures among the burrow casts analyzed (Table 2). This result suggests that higher sediment density allows more open burrows to be constructed thereby increasing the level of complexity of the burrow architecture.

Absence of sediment moisture was found to prevent the production of open burrows and resulted in the production of biogenic cross lamination when sediment density was also low (Table 1). These structures were not produced in the other sediment types in which the scorpions could produce open burrows. In these experiments, open burrows were excluded from the environment as a result of the nature of the sediment alone.

While sediment composition can be determined through sedimentological analysis, the original sediment density is more difficult to interpret. The morphology of biogenic structures produced by $\mathrm{H}$. arizonensis was directly related to sediment composition and density. The complexity of these burrows and potentially other burrows can therefore be considered as useful indicators of sediment density. Original moisture content is also difficult to assess. From the results of this study, the presence of biogenic cross lamination in a continental setting may be used to indicate very low moisture at well as low sediment density.

\section{SIGNIFICANCE}

\section{Recognition of Scorpion Burrows in the Fossil Record}

The interpretation of tracemakers from fossil burrows requires the recognition of architectural and surficial morphologies of burrows produced by modern animals. Scorpion burrows lack a significant fossil record despite the prevalence of burrow- ing scorpions in the modern and the long ranging evolutionary history of the group. This absence is likely the result of the failure to recognize these burrows. Ichnofossils are typically classified according to a set of ichnotaxobases, which include different aspects of their morphology including architecture, overall shape, orientation with respect to the substrate, surficial features such as wall ornamentation, and internal structure which includes constructed linings and active fill (Bertling et al., 2006). Other aspects of ichnofossils that have been used for identification include size, the type of substrate in which the trace was produced, style of preservation, type of passive fill, geologic age, and geographic location or facies occurrence. While these features are typically not considered ideal for classifying ichnofossils (Bertling et al., 2006), they are critical in their interpretation (Bromley, 1996).

Establishing a set of ichnotaxobases that can be useful in the identification, classification, and interpretation of a fossil burrow including the behaviors involved, tracemaker, and environmental conditions requires understanding the morphology of the burrows of modern organisms. The burrows produced by $H$. arizonensis in these experiments provide a starting set of ichnotaxobases that can be used to aid in the identification of scorpion burrows in the fossil record. The general ichnotaxobases for scorpion burrows indicated by this study include:

Architecture. Scorpion burrows can include subvertical ramps, U-shaped burrows, helical burrows, and mazeworks. These burrows include one to five surface openings, shafts, tunnels, and laterally expanded chambers.

Overall Shape. Shafts and tunnels are elliptical in cross section with a flattened base, curved walls, and a concave roof. Shafts and tunnels are two to three time wider than high. More vertically oriented $\left(30^{\circ}+\right)$ shafts tend to be straight, while tunnels may be sinuous and curve up to $40^{\circ}$ along a horizontal plane. Laterally expanded chambers are present at the end of the burrow or near the burrow entrance. Chambers have the same cross-sectional characteristics of tunnels and shafts but are three to five times wider than high. Branching is uncommon but it does occur in established and developing mazeworks. In these burrow types, side branches of tunnels occur but tend to be short and connect different elements of the mazework.

Orientation. Scorpion burrows range in orientation from nearly horizontal $\left(5-10^{\circ}\right)$, oblique $\left(30-45^{\circ}\right)$, 
and rarely vertical $\left(75-90^{\circ}\right)$ just below some burrow entrances.

Internal Structure. Burrows produced by scorpions possess no distinguishable lining. The boundary between the sediment matrix and the open burrow is abrupt and irregular. Fill may be active or passive. When active, some graded bedding may be present, but it is generally massive. More typically burrows were filled passively as a result of gravitational collapse of the burrow entrance and upper portion of the burrow shaft.

Surficial Features. No surface sculpture or bioglyphs were preserved along the walls of the burrows. The walls are characterized by an irregular texture imparted by the surrounding sediment; however the bottom of the tunnels and chambers tends to be smoother than the sides or top.

Some variation from these ichnotaxobases is expected with different genera or families of scorpions. Burrows of $P$. imperator, for example, are characterized by tunnels and shafts that are more elliptical in cross section with concave as opposed to flattened floors, lower width to height ratios of the different burrow elements, larger tunnels and chambers, and shafts and tunnels that are oriented more horizontally on average (Figure 13.1; Table 2 ). Despite these differences in details, however, the general ichnotaxobases are the same for both scorpions.

\section{Paleontologic and Paleoecologic Significance}

Ichnofossils generally have a greater preservation potential than body fossils because they are already buried within the sediment and do not possess elements that can decompose, disarticulate, or be transported elsewhere (Bromley, 1996). Burrows produced by $H$. arizonensis have a relatively high preservation potential because they can be deep structures, they can be produced in firm sediment and are resistant to collapse, and occupied burrows are continuously maintained. The preservation of one of these burrows does require a rapid influx of sediment with a contrasting lithology. This process can be common in arid and semi-arid environments where windblown clay, silt, and fine sand could gradually fill an open burrow. The same is true of coarser sediment transported by sudden floods.

Given the early evolutionary history of scorpions, their wide geographic and environmental distribution, and the general high preservation potential of trace fossils, scorpion burrows should be common in the fossil record. The absence of these structures from the literature is likely a bias resulting from a general failure to recognize them. The recognition of scorpion burrows in the fossil record would allow for a better understanding of the evolutionary and biographic history of this group of animals. While body fossils are relatively common in Paleozoic strata, they are much less common in Mesozoic and even Cenozoic rocks (Sissom, 1990). Those fossils that have been collected and described from these more recent time intervals are generally from amber (Petrunkevitch, 1955; Kjellesvig-Wearing, 1986; Sissom, 1990). By the Mesozioc, however, scorpions had taken on very modern morphologies, behaviors, and habitats (Sissom, 1990). The average size of scorpions was reduced to that of extant taxa and many are likely to have used burrows as permanent shelters as a result of this morphological change. The recognition of scorpion burrows from stratigraphically equivalent deposits may therefore be the best way to assess the true abundance and distribution of scorpion taxa.

The production of cross lamination by the scorpions in dry, loose sand provides another means of assessing hidden biodiversity. The presence of cross lamination is generally considered evidence of abiotic processes such as the movement of sediment by water or wind. These experiments show that these structures can be produced by animals as well. The specimens of $H$. arizonensis were able to laminate massive sand and clay through processes of bioturbation; this is the opposite if what is normally expected. Generally, laminated and cross laminated sediment are viewed as lacking burrowing infauna (Bromley, 1996). Similar structures have been observed in association with the burrowing of pistol shrimp in marine laboratory experiments (Mcllroy, 2010). To fully assess the origin of cross laminae in terrestrial environments, therefore, careful consideration of their distribution must be considered before interpretations are made.

Scorpions are important components of terrestrial ecosystems (Polis, 1990). They fill a fundamental role as intermediate predators in many modern ecosystems (McCormick and Polis, 1990). Scorpions feed on a wide variety of prey, particularly other arthropods, and also serve as prey for other large predators (McCormick and Polis, 1990). The presence of scorpions in a paleoenvironmental setting suggests the presence of at least minimal vegetation and arthropods, annelids, or even small vertebrates to support these carnivorous animals. The density of scorpions can be elevated in 
regions with a great abundance of prey animals, in some areas with 1-12 scorpions per square meter (McCormick and Polis, 1990). An increase in the density of scorpion burrows may then be used to infer the abundance of other arthropods. In semiarid and arid environments, scorpions like $H$. arizonensis represent the dominant insectivorous predators and are therefore vital to energy storage and transfer in these ecosystems (McCormick and Polis, 1990). In areas with small vertebrate populations such as islands, scorpions may even be the top predator (McCormick and Polis, 1990). A study by Marples and Shorthouse (1982) indicated that a population of the arid scorpion Urodacus yaschenkoi consumed an average of $7.90 \mathrm{~kg} / \mathrm{ha}$ of prey, representing approximately 100,000 ants or 32,000 spiders removed per hectare per year. The corresponding mass of the scorpion $U$. yaschenkoi is only $1.2-1.85 \mathrm{~kg} / \mathrm{ha}$. It has been estimated that $H$. arizonensis is capable of removing $106-160 \mathrm{~kg}$ of prey per year (McCormick and Polis, 1990). Given the importance of scorpions in modern ecosystems and the long evolutionary history of the group, the recognition of scorpion burrows would therefore provide for a better interpretation of fossil ecosystems.

These results of the experiments with burrowing scorpions are also significant because they demonstrate the problem with using absolute burrow size to make interpretations about potential tracemakers. It is quite common for fossil continental burrows with large $(>2 \mathrm{~cm})$ cross-sectional diameters to be interpreted as the product of vertebrate behavior simply on the basis of the size of the structure (e.g., Miller et al., 2001; Hasiotis et al., 2004; Loope, 2008; Storm et al., 2010; Talanda et al., 2011). In other instances, the presence of complex branching patterns has also been used to diagnose a vertebrate tracemaker (Miller et al., 2001; Hasiotis et al., 2004; Talanda et al., 2011). The experiments described in this paper have shown that scorpions are capable of producing burrows with large diameter tunnels and chambers as well as complex, interconnected burrow networks. These two criteria alone, therefore, cannot be used to diagnose a vertebrate burrow.

\section{Paleopedological and Paleoenvironmental Significance}

Observations made during these experiments have indicated that the burrowing activity of scorpions plays a role in pedogenesis. The burrowing activity of scorpions in the laboratory was restricted to depths associated with the A and upper B hori- zons $(0-20 \mathrm{~cm})$, but scorpion burrows have been found at depths as great as $2 \mathrm{~m}$ in natural settings (Polis, 1990).

The specimens of $H$. arizonensis facilitated the upward movement of sediment from the subsurface to the surface through their burrowing method. This resulted in the production of a loose, undulating surface topography, disrupted and destroyed primary sedimentary structures, and resulted in an overall mixing of the sediment. The excavation process also loosened the sediment fabric especially in the denser sediments increasing overall porosity and permeability both in the new surface layer and the subsurface along the walls of the burrow.

The excavation of large, permanent burrows produced large voids and channels in the subsurface that allowed for the migration of water and oxygen through the sediment profile. This process is critical in pedogenesis allowing for the dissolution of minerals as well as the transportation of ions and organics through the soil profile (Schaetzl and Anderson, 2009). These voids also allow for the upward movement of water as a result of evapotranspiration which is important for plant growth (Schaetzl and Anderson, 2009). Importantly, the scorpion burrows connection to the surface is actively maintained during occupation allowing for the continuous infiltration of water, sediment, organics, and other organisms into the subsurface. Even when the burrows are filled actively or passively after being abandoned, the fill is typically looser than the surrounding fabric and has a higher overall porosity and permeability due to the disruption by the scorpion. The filled burrows, therefore, continue to serve as conduits for the downward and upward migration fluids through the soil profile. The incorporation of organic material from feeding in the subsurface also provides a source of nutrients for soil microbes and other soil animals. While scorpions tend to consume most of the prey they capture and excrete very little waste (McCormick and Polis, 1990), there is still some organic material left behind within the burrow. Appendages of crickets were the most common organic debris found within the burrows of $H$. arizonensis in the lab experiments. This organic material is quickly broken down by microbes and incorporated into the surrounding soil adding important nutrients for other microbes and plants (Lavelle and Spain, 2005).

Fossil scorpion burrows would be preserved in continental terrestrial paleoenvironments. Due to the terraphilic nature of the tracemaker, these bur- 
rows would indicate the presence of a paleosol within the vadose zone (Hasiotis, 2007). The specific nature of the paleoenvironment (temperature, average precipitation, vegetation, soil type) would vary widely given the range of environments modern and fossil scorpions inhabit (Polis, 1990; Sissom, 1990). Therefore fossil scorpion burrows could be present in any soil type from Entisols to Oxisols. A possible exception would be Gelisols, or the soils of tundra environments where scorpions are not found in the modern (Polis, 1990; Sissom, 1990). Fossil scorpion burrows would be associated with a number of other ichnofossils including those of other arachnids (spiders, whip scorpions), other soil arthropods (millipedes, centipedes), and possible vertebrates, but fossil root traces would be the most common. The presence of modern scorpions within arid environments with minimal vegetation, however, means that the presence of fossil root traces is not required.

\section{CONCLUSIONS}

Continental neoichnological studies may be used to identify characteristic burrow morphologies indicative of specific behaviors, burrowing methods, and tracemakers. In all cases, the interpretation of ichnofossils is impossible without understanding the biogenic structures produced by extant organisms. Consequently, neoichnological studies have a vital role in the interpretation of paleosols and continental paleoenvironments.

Specimens of $H$. arizonensis produced four different burrow architectures dependent on sediment composition and moisture content including subvertical ramps, U-shaped burrows, helical burrows, and mazeworks. Despite the differences in overall architecture, the burrows had similar average internal dimensions and cross-sectional shapes. Overall, increasing sediment density was found to have a positive relationship with total burrow length, which resulted in the production of more complex burrow architectures in denser sediments. Open burrows could not be maintained within sediment with no moisture content, but when sediment density was also low biogenic cross lamination was produced.

The proper identification of large burrows from semi-arid to arid paleoenvironments requires understanding the behaviors of the organisms that inhabit these environments in the modern. Burrows of the size and complexity of those produced by the desert scorpions in these experiments would typically be attributed to vertebrates if preserved as ichnofossils. A major problem in properly interpreting continental ichnofossils is the lack of available information on the burrows produced by extant soil animals. This study also allows for the potential recognition of biogenically produced 'primary' sedimentary structures such as ripple cross lamination. These structures represent a type of 'hidden bioveristy,' structures which might otherwise be attributed to abiotic processes resulting in potentially missing an important component of the ecosystem, in this case a predatory arthropod.

\section{ACKNOWLEDGMENTS}

We thank the National Science Foundation (EAR-0844256) and the American Chemical Society Petroleum Research Fund (49387-UNI8) for their generous support provided to Dr. Hembree to conduct this and similar research. We thank A.A. Klompmaker and one anonymous reviewer for their helpful comments which improved this paper.

\section{REFERENCES}

Ahlbrandt, T.S., Andrews, S., and Gwynne, D.T. 1978. Bioturbation in eolian deposits. Journal of Sedimentary Petrology, 48:839-848.

Alexander, R.R., Stanton Jr., R.J., and Dodd, J.R. 1993. Influence of sediment grain size on the burrowing of bivalves: correlation with distribution and stratigraphic persistence of selected Neogene clams. Palaios, 8:289-303.

Bertling, M., Braddy, S.J., Bromley, R.G., Demathieu, G.R., Genise, J., Mikulas, R., Nielsen, J.K., Nielsen, K.S., Rindsberg, A.K., Schlirf, M., and Uchman, A. 2006. Names for trace fossils: a uniform approach. Lethaia, 39:265-286.

Bradley, R. 1982. Digestion time and reemergence in the desert grassland scorpion Paruroctonus utahensis (Williams) (Scorpionida, Vaejovidae). Oecologica, 55:316-318.

Brady, L.F. 1947. Invertebrate tracks from the Coconino Sandstone of northern Arizona. Journal of Paleontology, 21:466-472.

Bromley, R.G. 1996. Trace Fossils: Biology, Taphonomy, and Applications. Chapman and Hall, London.

Bub, K. and Bowerman, R.F. 1979. Prey capture by the scorpion Hadrurus arizonensis (Ewing) (Scorpiones: Vaejovidae). Journal of Arachnology, 7:243-253.

Counts, R.R. and Hasiotis, S.T. 2009. Neoichnological experiments with masked chafer beetles (Coleoptera: Scarabaeidae): Implications for backfilled continental trace fossils. Palaios, 24:74-91.

Curran, H.A. and Martin, A.J. 2003. Complex decapod burrows and ecological relationships in modern and Pleistocene intertidal carbonate environments, San Salvador Island, Bahamas. Palaeogeography, Palaeoclimatology, Palaeoecology, 192:229-245. 
Dashtgard, S.E., Gingras, M.K., and Pemberton, S.G. 2008. Grain-size control on the occurrence of bioturbation. Palaeogeography, Palaeoclimatology, Palaeoecology, 257:224-243.

Davis, R.B., Minter, N.J., and Braddy, S.J. 2007. The neoichnology of terrestrial arthropods. Palaeogeography, Palaeoclimatology, Palaoecology, 255:284307.

De, C. 2005. Biophysical model of intertidal beach crab burrowing: application and significance. Ichnos, 12:11-29.

Deocampo, D.M. 2002. Sedimentary structures generated by Hippopotamus amphibious in a lake-margin wetland, Ngorongoro Crater, Tanzania. Palaios, 17:212-217.

Dunlop, J.A., Penney, D., Tetlie, O.E., and Anderson, L.I. 2008. How many species of fossil arachnids are there? The Journal of Arachnology, 36:267-272.

Eastwood, E.B. 1978. Notes on the scorpion fauna of the Cape. IV, the burrowing activities of some scorpionids and buthids (Arachnida, Scorpionida). Annals of the South African Museum, 74:249-255.

Ekdale, A.A. and Berger, W.H. 1978. Deep-sea ichnofacies: modern organism traces on land and in pelagic carbonates of the western equatorial Pacific. Palaeogeography, Palaeoclimatology, Palaeoecology, 23:263-278

Frey, R.W. 1968. The Lebensspuren of some common marine invertebrates near Beaufort, North Carolina. 1, Pelecypod burrows. Journal of Paleontology, 42:570-574

Frey, R.W. 1970. The Lebensspuren of some common marine invertebrates near Beaufort, North Carolina. 2. Anemone burrows. Journal of Paleontology, 44:308-311.

Frey, R.W., Curran, H.A., and Pemberton, S.G. 1984. Tracemaking activities of crabs and their environmental significance: the ichnogenus Psilonichnus. Journal of Paleontology, 58:333-350.

Frey, R.W., Howard, J.D., and Hong, J.S. 1987. Prevalent lebensspuren on a modern macrotidal flat, Inchon, Korea: ethological and environmental significance. Palaios, 2:517-593.

Gaillard, C. 1991. Recent organism trace fossils and ichnofacies on the deep-sea floor off New Caleodonia, southwestern Pacific. Palaios, 6:302-315.

Gingras, M.K., MacEachern, J.A., and Pickerill, R. 2004. Modern perspectives on the Teredolites ichnofacies: observations from Willapa Bay, Washington. Palaios, 19:79-88.

Gingras, M.K., Pickerill, R., and Pemberton, S.G. 2002. Resin casts of modern burrows provides analogs for composite trace fossils. Palaios, 17:206-211.

Gingras, M.K., Lalond, S.V., Amskold, L., and Konhauser, K.O. 2007. Wintering chironomids mine oxygen. Palaios, 22:433-438.
Gobetz, K.E. 2005. Claw impressions in the walls of modern mole (Scalopus aquaticus) tunnels as a means to identify fossil burrows and interpret digging movements. Ichnos, 12:227-231.

Gregory, M.R., Balance, P.F., Gibson, G.W., and Ayling, A.M. 1979. On how some rays (Elasmobranchia) excavate feeding depressions by jetting water. Journal of Sedimentary Petrology, 49:1125-1130.

Hadley, N.F. 1970a. Water relations of the desert scorpion, Hardrurus arizonensis. Journal of Experimental Biology, 53:547-558.

Hadley, N.F. 1970b. Micrometeorology and energy exchange in two desert arthropods. Ecology, 51:434444.

Hadley, N.F. 1974. Adaptational biology of desert scorpions. Journal of Arachnology, 2:11-23.

Hadley, N.F. 1990. Environmental physiology, p. 321340. In Polis, G.A. (ed.), The Biology of Scorpions. Stanford University Press, Stanford.

Hadley, N.F. and Williams, S.C. 1968. Surface activities of some North American scorpions in relation to feeding. Ecology, 49:726-734.

Halfen, A.F. and Hasiotis, S.T. 2010. Neoichnological study of the traces and burrowing behaviors of the western harvester ant Pognomyrmex occidentalis (Insecta: Hymenoptera: Formicidea): paleopedogenic and paleoecologic implications. Palaios, 25:703-720.

Hammer, Ø. and Harper, D. 2006. Paleontolgical Data Analysis. Blackwell Publishing, Malden, Massachusetts.

Häntzschel, W. 1975. Trace fossils and problematica, $p$ 1-269. In Teichert, C. (ed.), Treatise on Invertebrate Paleontology, Part W. Miscellanea, Supplement I. Geological Society of America and University of Kansas Press, Lawrence.

Harrington, A. 1978. Burrowing biology of the scorpion Cheloctonus jonesii (Arachnida: Scorpionida: Scorpionidae). Journal of Arachnology, 5:243-249.

Hasiotis, S.T. 2003. Complex ichnofossils of solitary and social soil organisms: understanding their evolution and roles in terrestrial paleoecosystems. Palaeogeography, Palaeoclimatology, Palaeoecology, 192:259-320.

Hasiotis, S.T. 2007. Continental ichnology: fundamental processes and controls on trace fossil distribution, $p$. 268-284. In Miller III, W. (ed.), Trace Fossils: Concepts, Problems, Prospects. Elsevier, Amsterdam.

Hasiotis, S.T. and Mitchell, C.E. 1993. A comparison of crayfish burrow morphologies: Triassic and Holocene fossil, paleo- and neo-ichnological evidence, and the identification of their burrowing signatures. Ichnos, 2:291-314.

Hasiotis, S.T., Wellner, R.W., Martin, A.J., and Demko, T.M. 2004. Vertebrate burrows from Triassic and Jurassic continental deposits of North America and Antarctica: their paleoenvironmental and paleoecological significance. Ichnos, 11:103-124. 
Hembree, D.I. 2009. Neoichnology of burrowing millipedes: linking modern burrow morphology, organism behavior, and sediment properties to interpret continental ichnofossils. Palaios, 24:425-439.

Hembree, D.I. and Hasiotis, S.T. 2006. The identification and interpretation of reptile ichnofossils in paleosols through modern studies. Journal of Sedimentary Research, 76:575-588.

Hembree, D.I. and Hasiotis, S.T. 2007. Biogenic structures produced by sand-swimming snakes: a modern analog for interpreting continental ichnofossils. Journal of Sedimentary Research, 77: 389-397.

Hertweck, G., Wehrmann, A., and Liebezeit, G. 2007. Bioturbation structures of polychaetes in modern shallow marine environments and their analogues to Chondrites group traces. Palaeogeography, Palaeoclimatology, Palaeoecology, 245:382-389.

Hjelle, J.T. 1990. Anatomy and morphology, p. 9-63. In Polis, G.A. (ed.), The Biology of Scorpions. Stanford University Press, Stanford.

Jeram, A.J. 1994a. Scorpions from the Viséan of East Kirkton, West Lothian, Scotland, with a revision of the infraorder Mesoscorpionina. Transactions of the Royal Society of Edinburgh, Earth Science, 84:283288.

Jeram, A.J., 1994b. Carboniferous Orthosterni and their relationship to living scorpions. Palaeontology, 37:513-550.

Kanazawa, K. 1992. Adaptation of test shape for burrowing and locomotion in spatangoid echinoids. Palaeontology, 35:733-750.

Kjellesvig-Waering, E.N. 1986. A restudy of the fossil Scorpionida of the world. Palaeontographica Americana, 55:1-287.

Koch, L.E. 1978. A comparative study of the structure, function, and adaptation to different habitats of burrows in the scorpion genus Urodacus (Scorpionida, Scorpionidae). Records of the Western Australian Museum, 6:119-146.

Lamoral, B.H. 1979. The scorpions of Namibia (Arachnida: Scorpionida). Annals of the Natal Museum, 23:497-784.

Lavelle, P. and Spain, A.V. 2005. Soil Ecology. Springer, Dordrecht.

Lawfield, A.M.W. and Pickerill, R.K. 2006. A novel contemporary fluvial ichnocoenose: unionid bivalves and the Scoyenia-Mermia ichnofacies transition. Palaios, 21:391-396.

Lighton, J.R.B, Brownell, P.H., Joos, B., and Turner, R.J. 2001. Low metabolic rate in scorpions: implications for population biomass and cannibalism. The Journal of Experimental Biology, 204:607-613.

Loope, D.B. 2008. Life beneath the surfaces of active Jurassic dunes: burrows from the Entrada Sandstone of south-central Utah. Palaios, 23:411-419.

Marples T.G. and Shorthouse, D.J. 1982. An energy and water budget for a population of arid zone scorpion Urodacus yaschenkoi (Birula, 1903). Australian Journal of Ecology, 7:119-127.
Martin, A.J. 2006. Resting traces of Ocypode quadrata associated with hydration and respiration: Sapelo Island, Georgia, USA. Ichnos, 13:57-67.

McCormick, S.J. and Polis, G.A. 1990. Prey, predators, and parasites, p. 294-320. In Polis, G.A. (ed.), The Biology of Scorpions. Stanford University Press, Stanford.

Mcllroy, D. 2010. Biogenic cross-lamination produced by the pistol-shrimp Alpheus bellulus in microcosm experiments. Journal of Sedimentary Research, 80:151-154.

Meadows, P.S. 1991. The environmental impact of burrows and burrowing animals - conclusions and a model, p. 327-338. In Meadows, P.S. and Meadows, A. (eds.), The Environmental Impact of Burrowing Animals and Animal Burrows. Clarendon Press, Oxford.

Meyer, R.C. 1999. Helical burrows as a palaeoclimate response: Daimonelix by Palaeocastor. Palaeogeography, Palaeoclimatology, Palaeoecology, 147:291298.

Miller, M.F., Hasiotis, S.T., Babcock, L.E., Isbell, J.L., and Collinson, J.W. 2001. Tetrapod and large burrows of uncertain origin in Triassic high paleolatitude floodplain deposits, Antarctica. Palaios, 16:218-232.

Needham, S.J., Worden, R.H., and Mcllroy, D. 2005. Experimental production of clay rims by macrobiotic sediment ingestion and excretion processes. Journal of Sedimentary Research, 75: 1028-1037.

Newlands, G. 1969. Scorpion defensive behavior. African Wildlife, 23:147-153.

O'Geen, A.T. and Busacca, A.J. 2001. Faunal burrows as indicators of paleo-vegetation in eastern Washington, USA. Palaeogeography, Palaeoclimatology, Palaeoecology, 169:23-37.

Osgood, Jr., R.G. 1975. The paleontological significance of trace fossils, p. 87-108. In Frey, R.W. (ed.), The Study of Trace Fossils: A Synthesis of Principles, Problems, and Procedures in Ichnology. SpringerVerlag, New York.

Pearson, N.J., Gingras, M.K., Armitage, I.A., and Pemberton, S.G. 2007. Significance of Atlantic sturgeon feeding excavations, Mary's Point, Bay of Fundy, New Brunswick, Canada. Palaios, 22: 457-464.

Pemberton, S.G. and Frey, R.W. 1985. The Glossifungites ichnofacies: modern examples from the Georgia coast, U.S.A, p. 237-259. In Curran, H.A. (ed.), Biogenic Structures: Their Use in Interpreting Depositional Environments. Society of Economic Paleontologists and Mineralogists Special Publication 35, Tulsa.

Pemberton, S.G., Spila, M., Pulham, A.J., Saunders, T., MacEachern, J.A., Robbins, D., and Sinclair, I.K. 2001. Ichnology and Sedimentology of Shallow to Marginal Marine Systems: Ben Nevis and Avalon Reservoirs, Jeanne d'Arc Basin. Geological Association of Canada, Newfoundland. 
Petrunkevitch, A. 1955. Arachnida, p. 42-162. In Moore, R.C. (ed.), Treatise on Invertebrate Paleontology, Part P, Arthropoda 2. Geological Society of American and University of Kansas Press, Lawrence.

Picard, M.D. 1977. Stratigraphic analysis of the Navajo Sandstone: a discussion. Journal of Sedimentary Petrology, 47:475-483.

Polis, G.A. 1980. Seasonal patterns and age specific variation in the surface activity of a population of desert scorpions in relation to environmental factors. Journal of Animal Ecology, 49:1-18.

Polis, G.A. 1990. Ecology, p. 247-293. In Polis, G.A. (ed.), The Biology of Scorpions. Stanford University Press, Stanford.

Polis, G.A. and Sissom, W.D. 1990. Life history, p. 161223. In Polis, G.A. (ed.), The Biology of Scorpions. Stanford University Press, Stanford.

Polis, G.A., Myers, C., and Quinlan, M. 1986. Burrowing biology and spatial distribution of desert scorpions. Journal of Arid Environments, 10:137-146.

Ratcliffe, B.C. and Fagerstrom, J.A. 1980. Invertebrate lebensspuren of Holocene floodplains: their morphology, origin, and paleoecological significance. Journal of Paleontology, 54:614-630.

Rodríguez-Tovar, F.J. 2007. Substrate firmness controlling nesting behavior of Bembix oculata (Hymenoptera, Bembicinae), p. 353-359. In Bromley, R.G., Buatois, L.A., Mángano, G., Genise, J.F., and Melchor, R.N. (eds.), Sediment-Organism Interactions: A Multifaceted Ichnology. Society for Sedimentary Geology Special Publication No. 58, Tulsa.

Rutin, J. 1996. The burrowing activity of scorpions (Scorpio maurus palmatus) and their potential contribution to the erosion of Hamra soils in Karkur, central Isreal. Geomorphology, 15:159-168.

Schaetzl, R. and Anderson, S. 2009. Soils: Genesis and Geomorphology. Cambridge University Press, Cambridge.

Scott, J.J., Renault, R.W., and Owen, R.B. 2007. Biogenic activity, trace formation, and trace taphonomy in the marginal sediments of saline, alkaline Lake Bogoria, Kenya Rift Valley, p. 311-332. In Bromley, R.G., Buatois, L.A., Mángano, G., Genise, J.F., and Melchor, R.N. (eds.), Sediment-Organism Interactions: A Multifaceted Ichnology. Society for Sedimentary Geology Special Publication No. 58, Tulsa.

Seike, K. and Nara, M. 2007. Occurrence of bioglyphs on Ocypode crab burrows in a modern sandy beach and its palaeoenvironmental implications. Palaeogeography, Palaeoclimatology, Palaeoecology, 252:458-463.

Seilacher, A. and Seilacher, E. 1994. Bivalvian trace fossils: a lesson from actuo-paleontology. Courier Forschungsinstitut Senckenberg, 169:5-15.

Shachak, M. and Brand, S. 1983. The relationship between sit and wait foraging strategy and dispersal in the desert scorpion, Scorpio maurus palmatus. Oecologica, 60:371-377.
Shorthouse, D.J. and Marples, T.G. 1980. Observations on the burrow and associated behavior of the aridzone scorpion Urodacus yaschenkoi (Birula). Australian Journal of Zoology, 28:581-590.

Sissom, W.D. 1990. Systematics, biogeography, and paleontology, p. 64-160. In Polis, G.A. (ed.), The Biology of Scorpions. Stanford University Press, Stanford.

Smith, R.M.H. 1987. Helical burrow casts of therapsid origin from the Beaufort Group

(Permian) of South Africa. Palaeogeography, Palaeoclimatology, Palaeoecology, 60:155-170.

Smith, J.J. and Hasiotis, S.T. 2008. Traces and burrowing behaviors of the cicada nymph Cicadetta calliope: neoichnology and paleoecological significance of extant soil-dwelling insects. Palaios, 23:503-513.

Stahnke, H.L. 1966. Some aspects of scorpion behavior. Bulletin of the Southern California Academy of Sciences, 65:65-80.

Storm, L., Mattathias, D.N., Smith, C.J., Fillmore, D.L., Szajna, M., Simpson, E.L., and Lucas, S.G., 2010. Large vertebrate burrow from the Upper Mississippian Mauch Chunk Formation, eastern Pennsylvania, USA. Palaeogeography, Palaeoclimatology, Palaeoecology, 298:341-347.

Tałanda, M., Dzięcioł, S., Sulej, T., and Niedźwiedzki, G. 2011. Vetebrate burrow system from the Upper Triassic of Poland. Palaios, 26:99-105.

Tallarovic, S.K., Melvile, J.M., and Brownwell, P.H. 2000. Courtship and mating in the giant hairy desert scorpion, Hadrurus arizonensis (Scorpionida, luridae). Journal of Insect Behavior, 13:827-838.

Tourtlotte, G. 1974. Studies on the biology and ecology of the northern scorpion Paruroctorus boreus (Girard). Great Basin Naturalist, 34:167-179.

Tschinkel, W.R. 2003. Subterranean ant nests: trace fossil past and future. Palaeogeography, Palaeoclimatology, Palaeoecology, 192:321-333.

Uchmanm A. and Pervesler, P. 2006. Surface lebensspuren produced by amphipods and isopods (crustaceans) from the Isonzo delta tidal flat, Italy. Palaios, 21:384-390.

Warburg, M.R. and Polis, G.A. 1990. Behavioral responses, rhythms, and activity patterns, p. 224246. In Polis, G.A. (ed.), The Biology of Scorpions. Stanford University Press, Stanford.

White, C.R. 2001. The energetics of burrow excavation by the inland robust scorpion, Urodacus yaschenkoi (Birula, 1903). Australian Journal of Zoology, 49:663674.

Williams, S.C. 1966. Burrowing activities of the scorpion Anuroctonus phaeodactylus (Wood) (Scorpionida: Vaejovidae). Proceedings of the California Academy of Sciences, 34:419-428. 


\section{TABLE CAPTIONS}

TABLE 4. Spearman's rank order analysis results comparing eight quantitative burrow properties $(\mathrm{X})$ with sediment density $(Y)$. Sediment density is ranked from 1

\section{Complexity vs. Sediment Density}

\begin{tabular}{cccc} 
Raw Score & \multicolumn{3}{c}{ Rank } \\
\hline $\mathbf{X}$ & $\mathbf{Y}$ & $\mathbf{X}$ & $\mathbf{Y}$ \\
\hline 3 & 3 & 6.5 & 14 \\
9 & 3 & 16.5 & 14 \\
9 & 3 & 16.5 & 14 \\
3 & 3 & 6.5 & 14 \\
7 & 3 & 15 & 14 \\
3 & 3 & 6.5 & 14 \\
4 & 3 & 13.5 & 14 \\
4 & 2 & 13.5 & 7.5 \\
3 & 2 & 6.5 & 7.5 \\
3 & 2 & 6.5 & 7.5 \\
3 & 2 & 6.5 & 7.5 \\
3 & 2 & 6.5 & 7.5 \\
3 & 2 & 6.5 & 7.5 \\
3 & 1 & 6.5 & 2.5 \\
3 & 1 & 6.5 & 2.5 \\
3 & 1 & 6.5 & 2.5 \\
3 & 1 & 6.5 & 2.5 \\
& 2 & &
\end{tabular}

Rs $=0.54$ $\left(0.4-0.7 \mathrm{kgf} / \mathrm{cm}^{2}\right), 2\left(1.1-1.4 \mathrm{kgf} / \mathrm{cm}^{2}\right)$, and $3(2.1-3.2$ $\left.\mathrm{kgf} / \mathrm{cm}^{2}\right)$.

2. Tortuosity vs. Sediment Density

\begin{tabular}{cccc} 
Raw Score & \multicolumn{3}{c}{ Rank } \\
\hline $\mathbf{X}$ & $\mathbf{Y}$ & $\mathbf{X}$ & $\mathbf{Y}$ \\
\hline 9 & 3 & 17 & 14 \\
1.4 & 3 & 11 & 14 \\
1.8 & 3 & 13.5 & 14 \\
3.3 & 3 & 15.5 & 14 \\
1.1 & 3 & 3 & 14 \\
3.3 & 3 & 15.5 & 14 \\
1.4 & 3 & 11 & 14 \\
1.3 & 2 & 8.5 & 7.5 \\
1.3 & 2 & 8.5 & 7.5 \\
1.1 & 2 & 3 & 7.5 \\
1.2 & 2 & 6.5 & 7.5 \\
1.4 & 2 & 11 & 7.5 \\
1.2 & 2 & 6.5 & 7.5 \\
1.1 & 1 & 3 & 2.5 \\
1.1 & 1 & 3 & 2.5 \\
1.1 & 1 & 3 & 2.5 \\
1.5 & 1 & 13.5 & 2.5 \\
& & &
\end{tabular}

$\mathrm{Rs}=0.58$ 
Hembree et Al.: NEOICHNOLOgy OF SCORPIONS

3. Circumference vs. Sediment Density

\begin{tabular}{cccc} 
Raw Score & \multicolumn{3}{c}{ Rank } \\
\hline $\mathbf{X}$ & $\mathbf{Y}$ & $\mathbf{X}$ & $\mathbf{Y}$ \\
\hline 15 & 3 & 16 & 14 \\
13.1 & 3 & 14 & 14 \\
12.2 & 3 & 8 & 14 \\
9 & 3 & 1 & 14 \\
12.3 & 3 & 9 & 14 \\
17.3 & 3 & 17 & 14 \\
12.9 & 3 & 13 & 14 \\
11 & 2 & 4 & 7.5 \\
11.9 & 2 & 7 & 7.5 \\
13.9 & 2 & 15 & 7.5 \\
11.5 & 2 & 6 & 7.5 \\
12.5 & 2 & 10 & 7.5 \\
12.6 & 2 & 11 & 7.5 \\
11.2 & 1 & 5 & 2.5 \\
12.7 & 1 & 12 & 2.5 \\
9.4 & 1 & 2 & 2.5 \\
10 & 1 & 3 & 2.5 \\
& 2 & &
\end{tabular}

$\mathrm{Rs}=0.44$
4. Total Length vs. Sediment Density

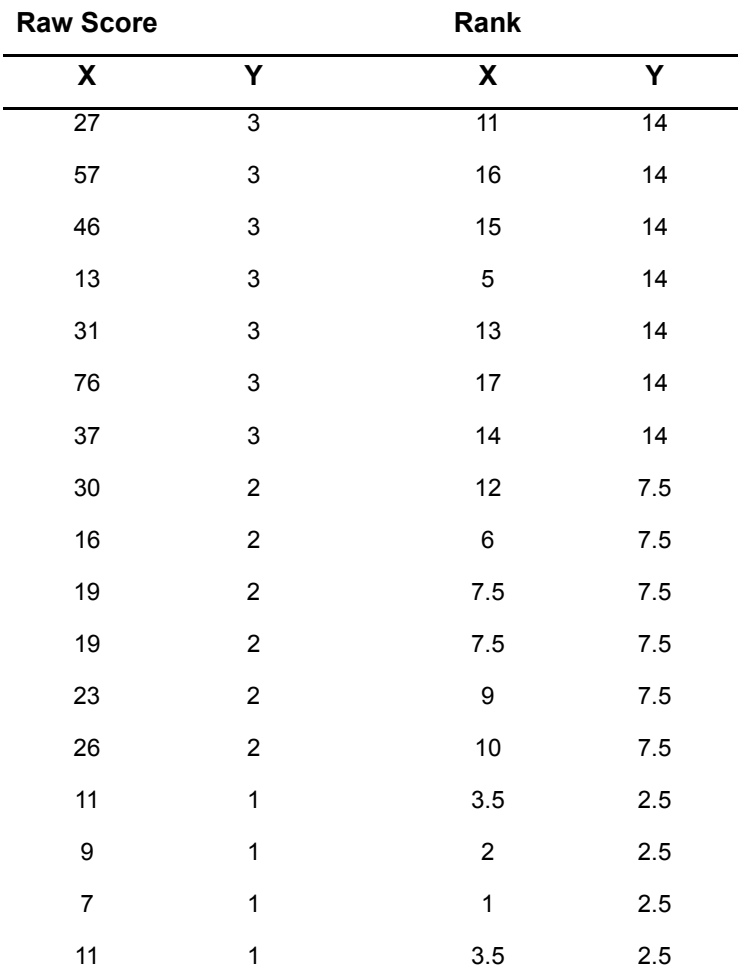

$\mathrm{Rs}=0.82$ 
PALAEO-ELECTRONICA.ORG

5. Maximum Width vs. Sediment Density

\begin{tabular}{cccc} 
Raw Score & \multicolumn{3}{c}{ Rank } \\
\hline $\mathbf{X}$ & $\mathbf{Y}$ & $\mathbf{X}$ & $\mathbf{Y}$ \\
\hline 7.7 & 3 & 17 & 14 \\
4.6 & 3 & 5 & 14 \\
6.4 & 3 & 13 & 14 \\
3.3 & 3 & 1 & 14 \\
7.2 & 3 & 16 & 14 \\
5.3 & 3 & 8 & 14 \\
6.2 & 3 & 12 & 14 \\
4.2 & 2 & 2 & 7.5 \\
5.2 & 2 & 7 & 7.5 \\
6.5 & 2 & 14 & 7.5 \\
4.9 & 2 & 6 & 7.5 \\
6.7 & 2 & 15 & 7.5 \\
5.4 & 2 & 9 & 7.5 \\
4.3 & 1 & 3 & 2.5 \\
6 & 1 & 11 & 2.5 \\
5.9 & 1 & 10 & 2.5 \\
4.4 & 1 & 4 & 2.5 \\
& 2 & &
\end{tabular}

$\mathrm{Rs}=0.26$
6. Maximum Height vs. Sediment Density

\begin{tabular}{cccc} 
Raw Score & \multicolumn{3}{c}{ Rank } \\
\hline $\mathbf{X}$ & $\mathbf{Y}$ & $\mathbf{X}$ & $\mathbf{Y}$ \\
\hline 3.2 & 3 & 15 & 14 \\
2.3 & 3 & 7.5 & 14 \\
3.1 & 3 & 14 & 14 \\
1.4 & 3 & 1 & 14 \\
2.6 & 3 & 10.5 & 14 \\
3.3 & 3 & 16.5 & 14 \\
2.8 & 3 & 12.5 & 14 \\
2.5 & 2 & 9 & 7.5 \\
2.1 & 2 & 5 & 7.5 \\
3.3 & 2 & 16.5 & 7.5 \\
2.6 & 2 & 10.5 & 7.5 \\
2.3 & 2 & 7.5 & 7.5 \\
2.2 & 2 & 6 & 7.5 \\
2.8 & 1 & 12.5 & 2.5 \\
1.9 & 1 & 3 & 2.5 \\
1.6 & 1 & 2 & 2.5 \\
2 & 1 & 4 & 2.5 \\
& & &
\end{tabular}

$\mathrm{Rs}=0.43$ 
Hembree et al.: Neoichnology of SCORPIONS

7. Maximum Depth vs. Sediment Density

\begin{tabular}{cccc} 
Raw Score & \multicolumn{3}{c}{ Rank } \\
\hline $\mathbf{X}$ & $\mathbf{Y}$ & $\mathbf{X}$ & $\mathbf{Y}$ \\
\hline 7.2 & 3 & 13 & 14 \\
7.4 & 3 & 14 & 14 \\
6.7 & 3 & 11 & 14 \\
4.6 & 3 & 9 & 14 \\
8.4 & 3 & 16 & 14 \\
16 & 3 & 17 & 14 \\
5.3 & 3 & 10 & 14 \\
8 & 2 & 15 & 7.5 \\
3 & 2 & 2 & 7.5 \\
3.4 & 2 & 3 & 7.5 \\
4 & 2 & 5 & 7.5 \\
4.2 & 2 & 6.5 & 7.5 \\
6.8 & 2 & 12 & 7.5 \\
3.9 & 1 & 4 & 2.5 \\
2.8 & 1 & 1 & 2.5 \\
4.3 & 1 & 8.5 & 2.5 \\
4.2 & 1 & & 2.5 \\
& 2 & 5 &
\end{tabular}

$R s=0.68$
8. Average Slope vs. Sediment Density

\begin{tabular}{cccc} 
Raw Score & \multicolumn{3}{c}{ Rank } \\
\hline $\mathbf{X}$ & $\mathbf{Y}$ & $\mathbf{X}$ & $\mathbf{Y}$ \\
\hline 15 & 3 & 9.5 & 14 \\
27 & 3 & 14 & 14 \\
37 & 3 & 16 & 14 \\
20 & 3 & 12 & 14 \\
30 & 3 & 15 & 14 \\
13 & 3 & 8 & 14 \\
10 & 3 & 6 & 14 \\
45 & 2 & 17 & 7.5 \\
5 & 2 & 2 & 7.5 \\
5 & 2 & 2 & 7.5 \\
10 & 2 & 6 & 7.5 \\
10 & 2 & 6 & 7.5 \\
8 & 2 & 4 & 7.5 \\
20 & 1 & 12 & 2.5 \\
5 & 1 & 2 & 2.5 \\
15 & 1 & 9.5 & 2.5 \\
20 & 1 & 12 & 2.5 \\
& & &
\end{tabular}

$\mathrm{Rs}=0.31$ 